Supplement of Ocean Sci. Discuss., 12, 2283-2313, 2015

http://www.ocean-sci-discuss.net/12/2283/2015/

doi:10.5194/osd-12-2283-2015-supplement

(C) Author(s) 2015. CC Attribution 3.0 License.

(c) (1)

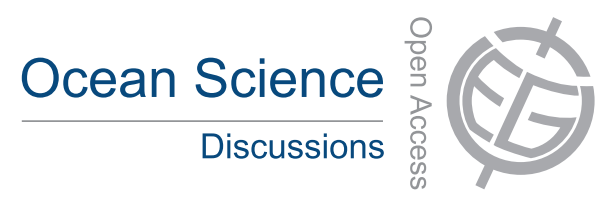

Supplement of

\title{
Remote sensing of chlorophyll in the Baltic Sea at basin scale from 1997 to 2012 using merged multisensor data
}

\section{J. Pitarch et al.}

Correspondence to: J. Pitarch (jaime.pitarchportero@artov.isac.cnr.it)

The copyright of individual parts of the supplement might differ from the CC-BY 3.0 licence. 


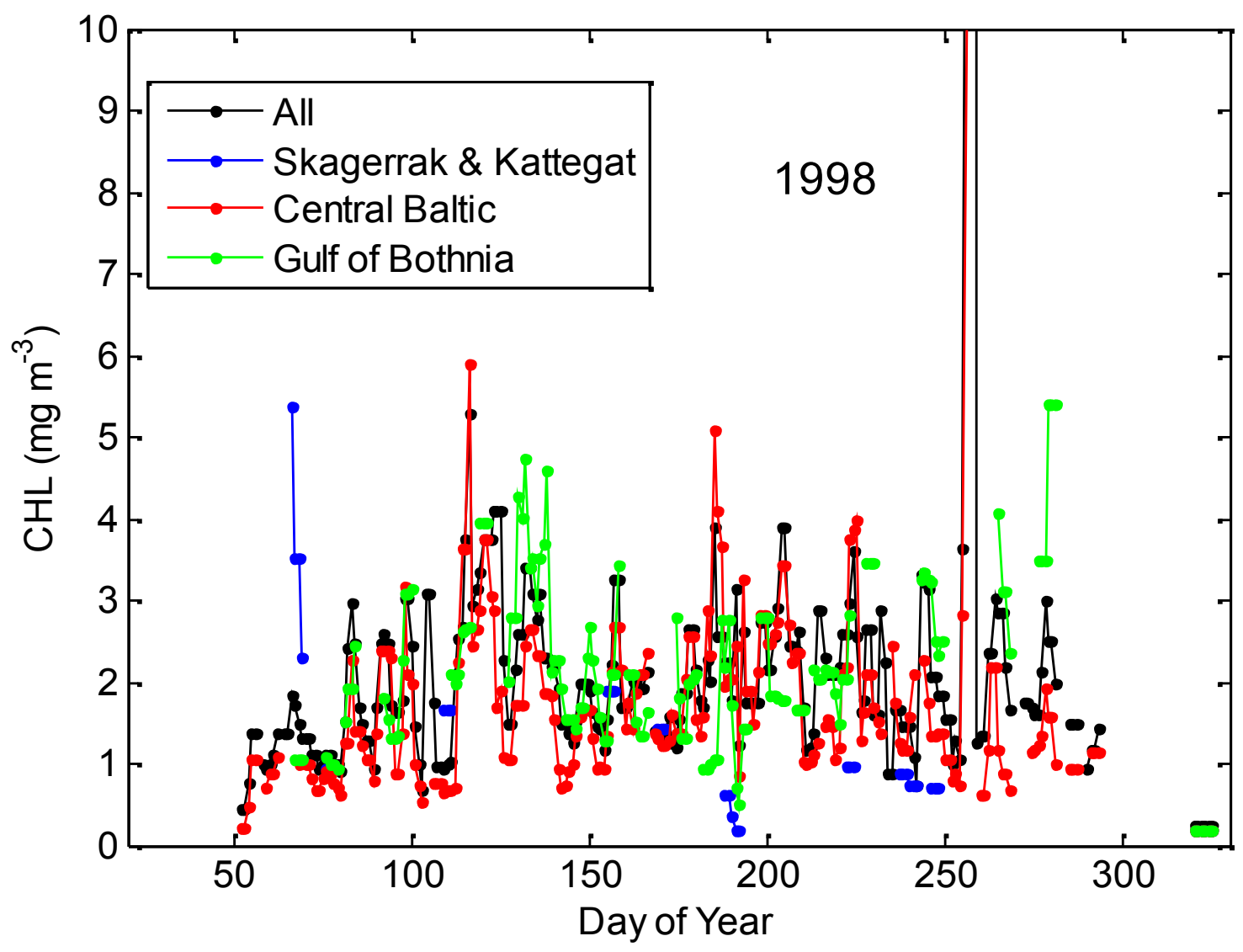

Fig. S1 CHL basin averages in 1998.

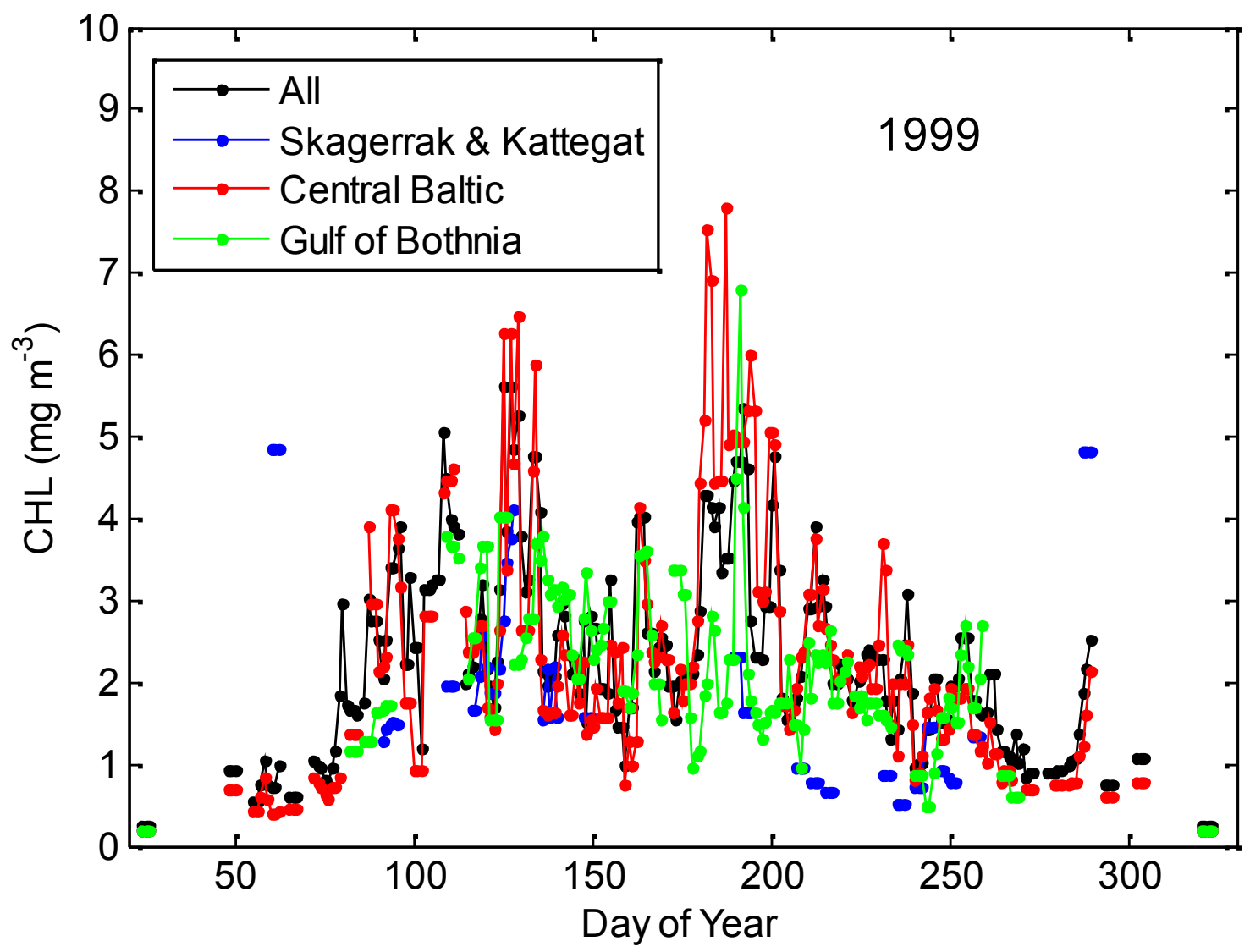

Fig. S2 CHL basin averages in 1999. 


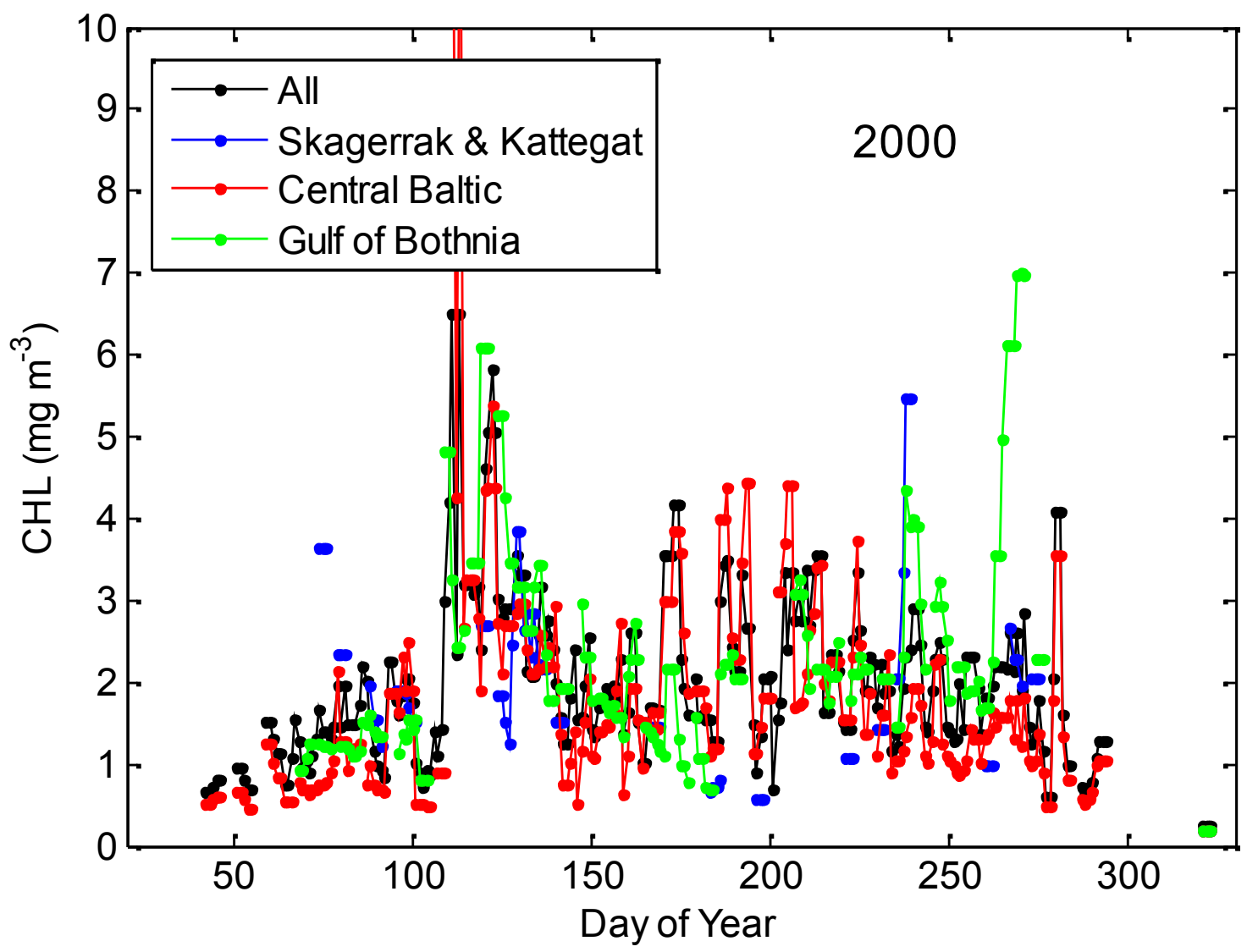

Fig. S3 CHL basin averages in 2000.

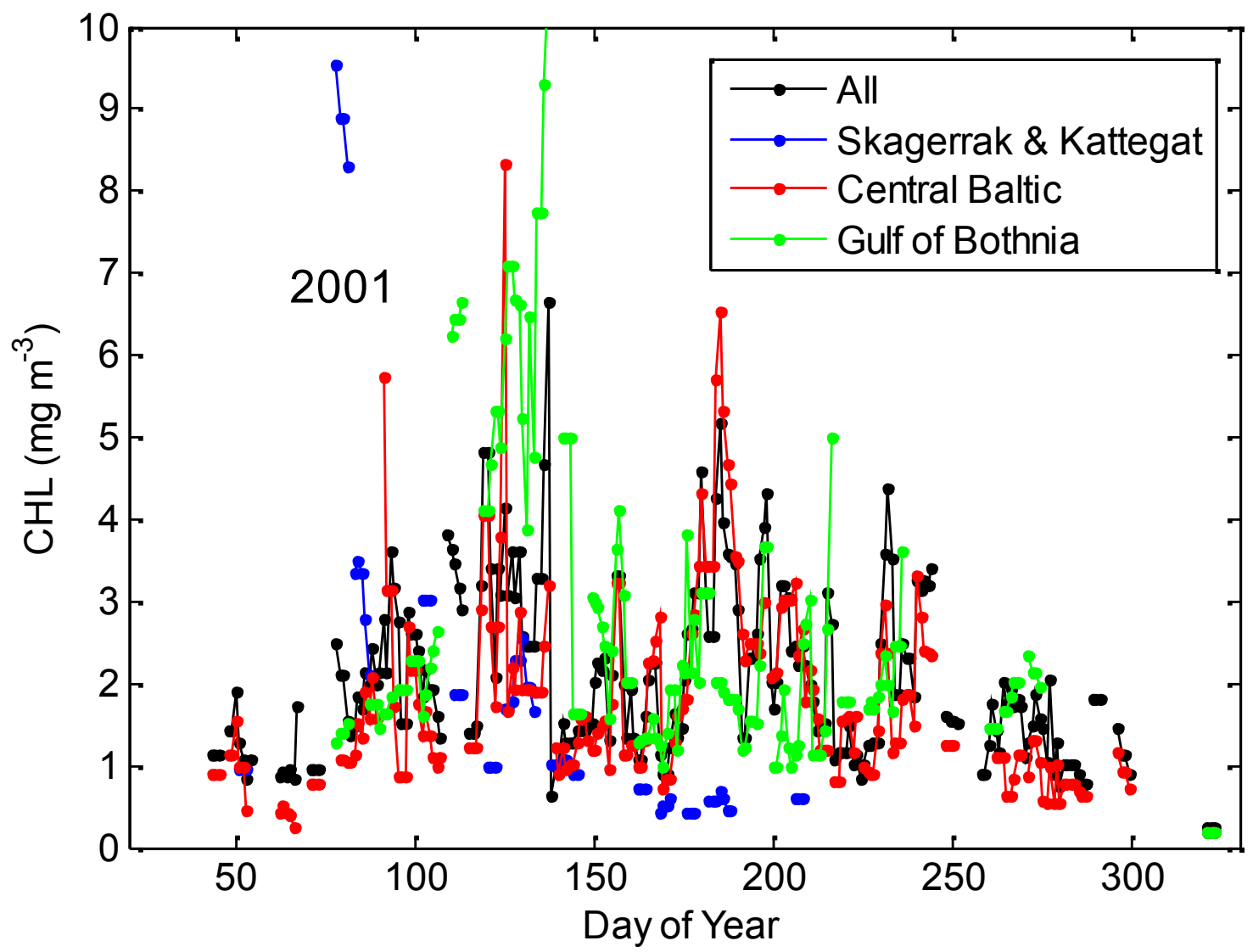

Fig. S4 CHL basin averages in 2001. 


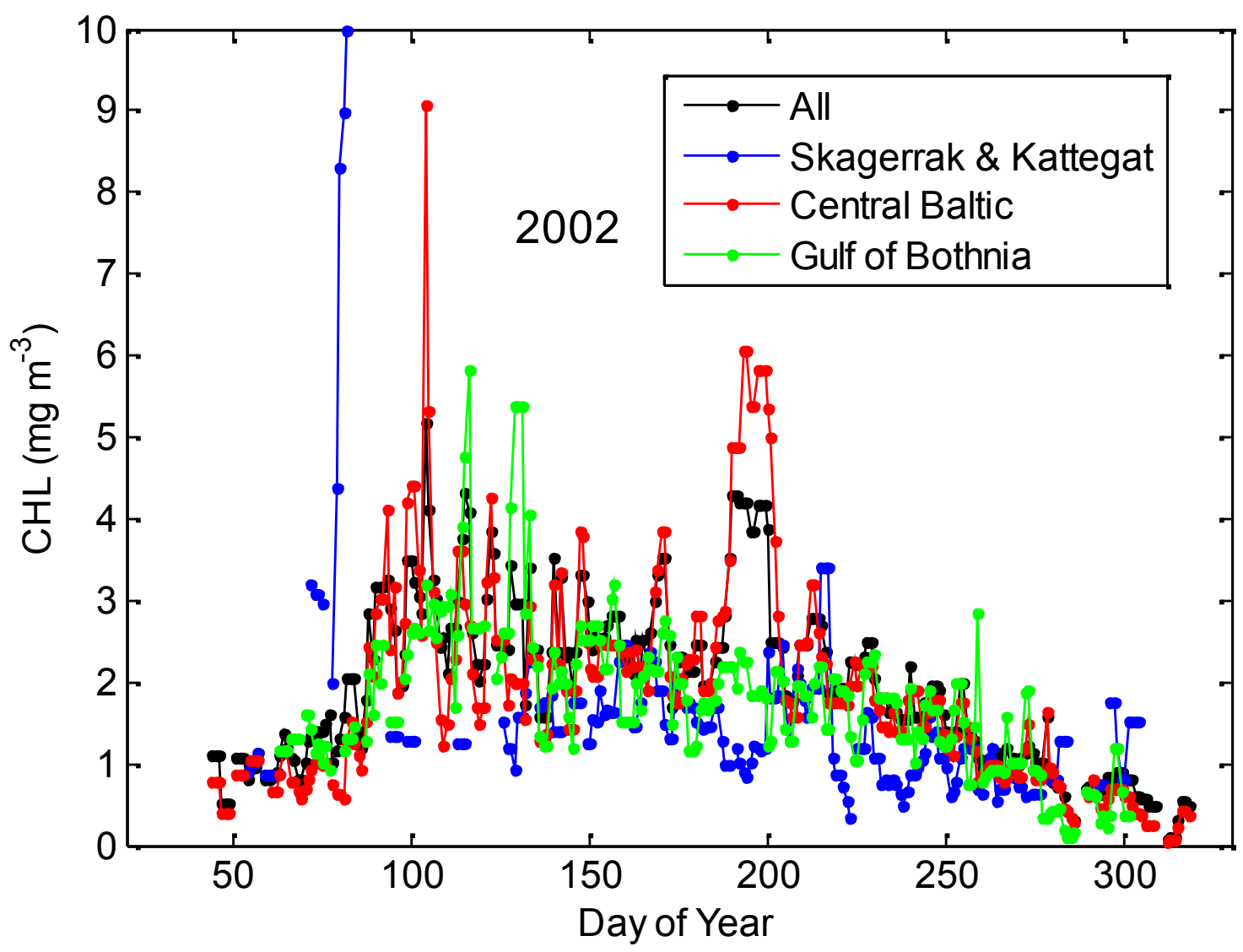

Fig. S5 CHL basin averages in 2002.

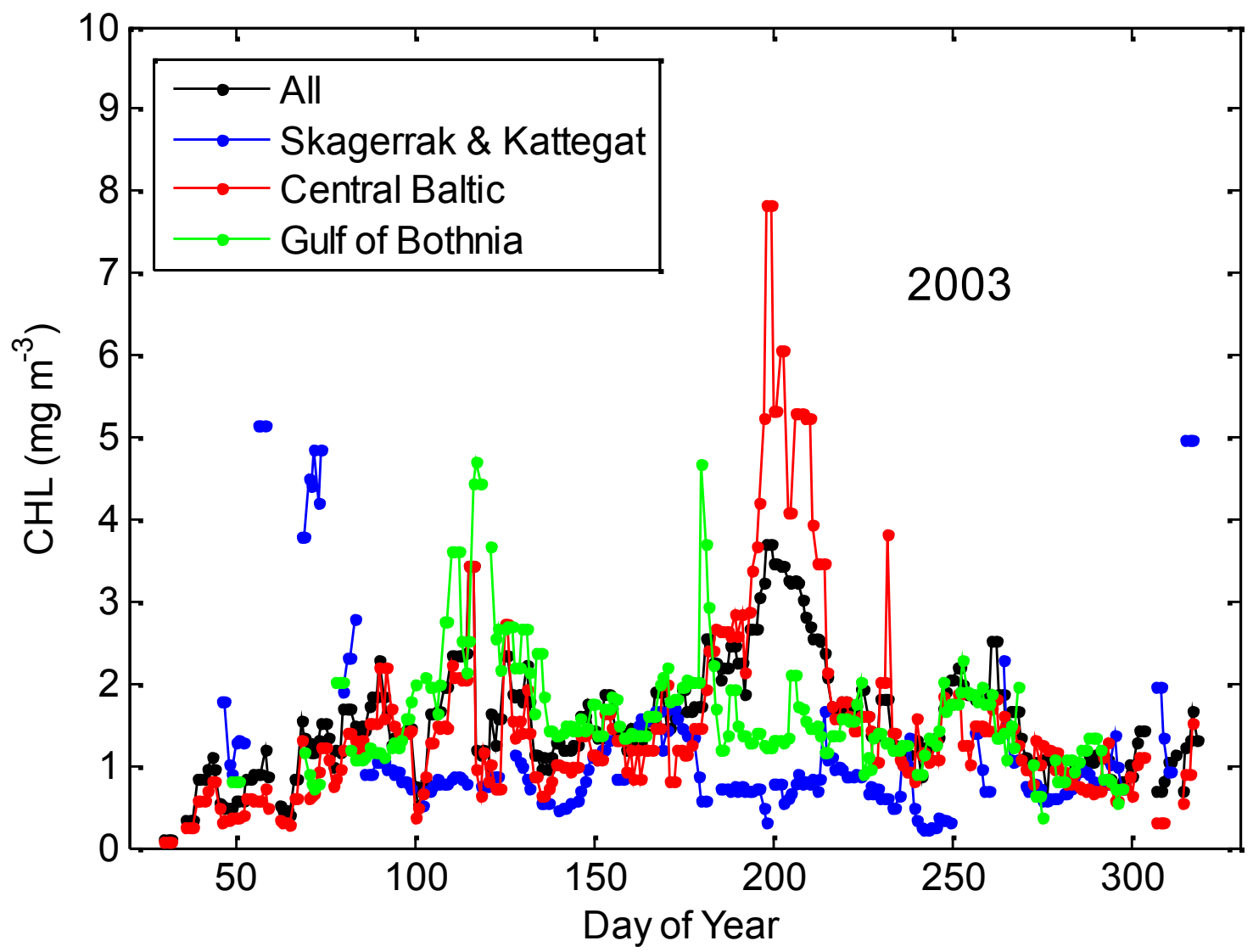

Fig. S6 CHL basin averages in 2003. 


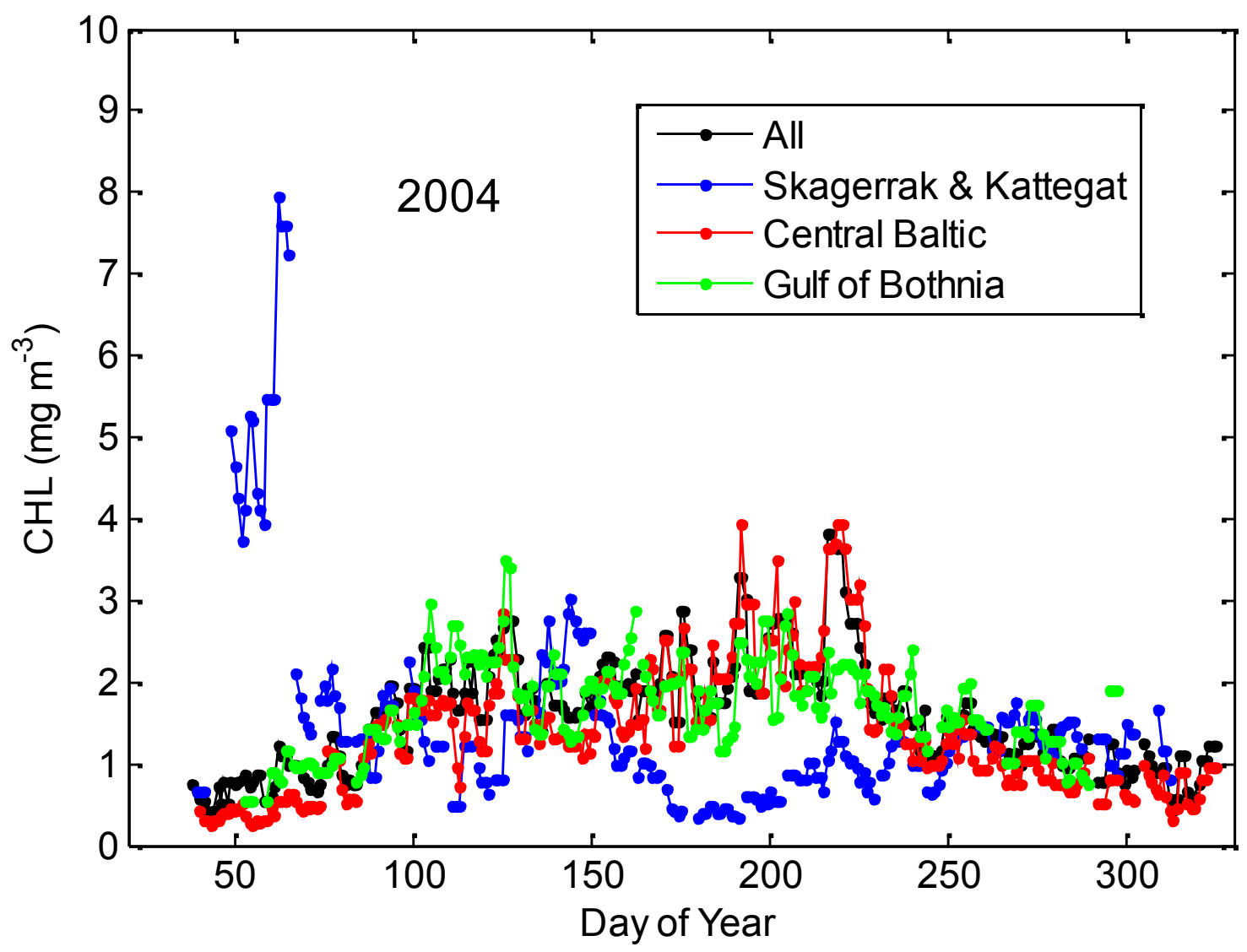

Fig. S7 CHL basin averages in 2004.

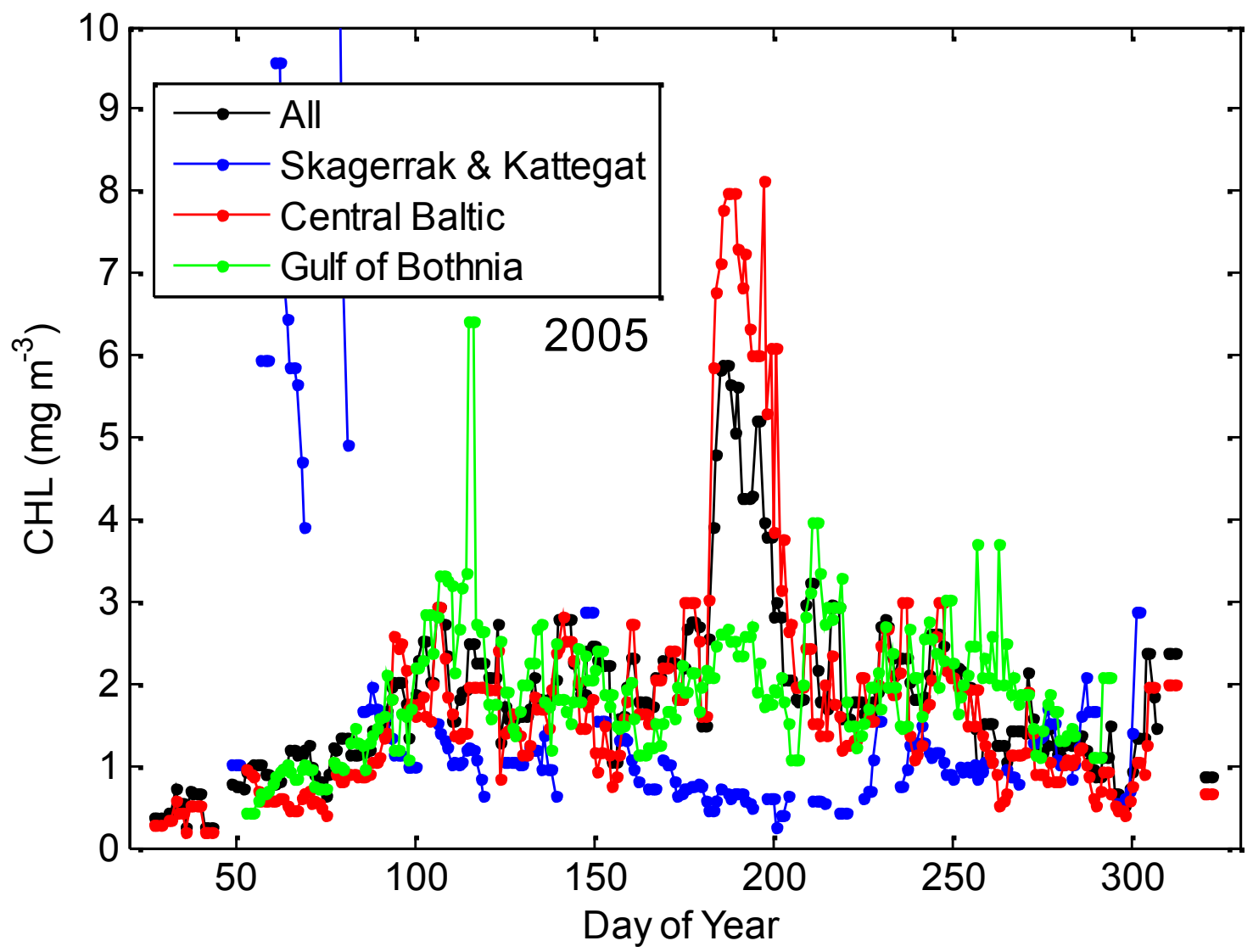

Fig. S8 CHL basin averages in 2005. 


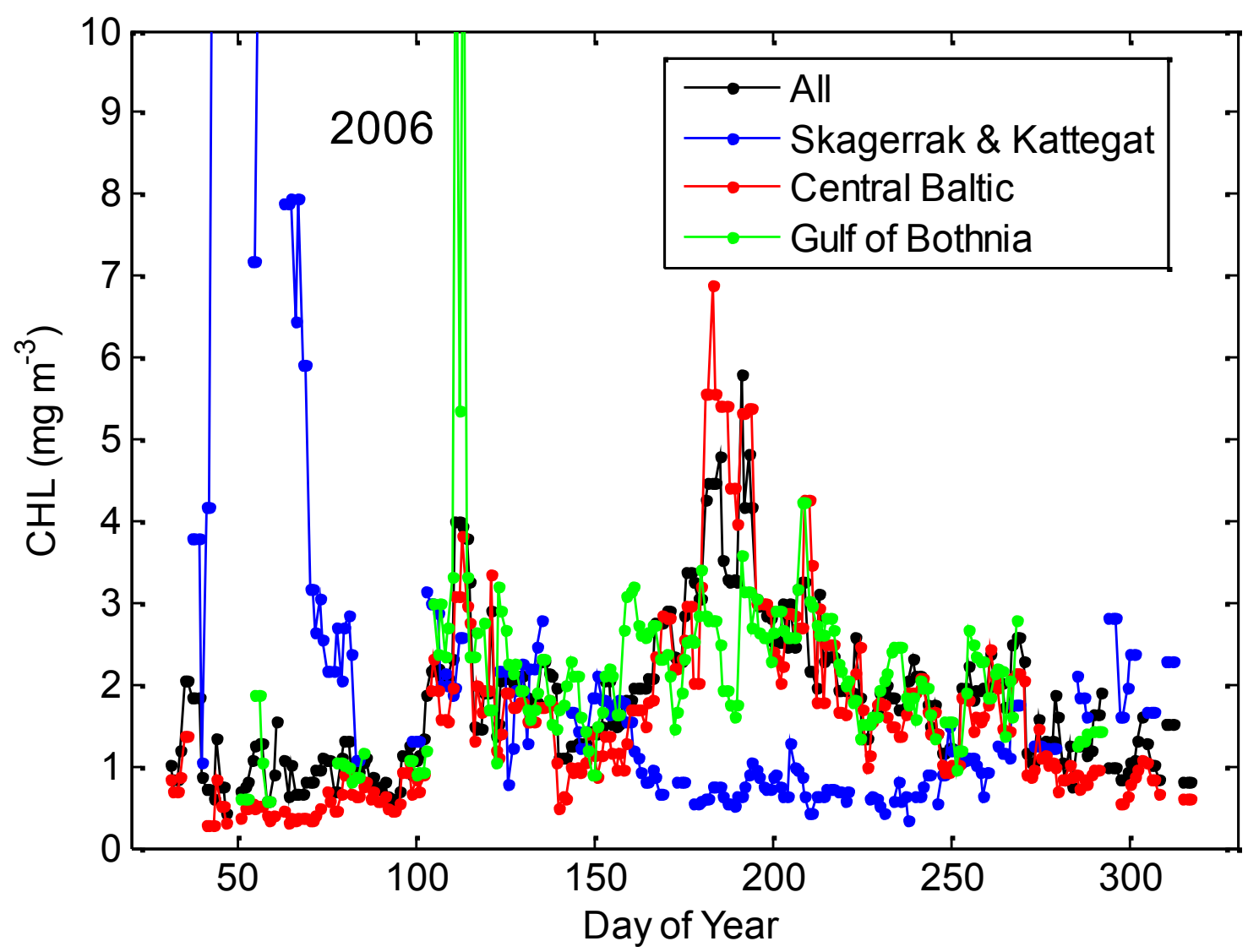

Fig. S9 CHL basin averages in 2006.

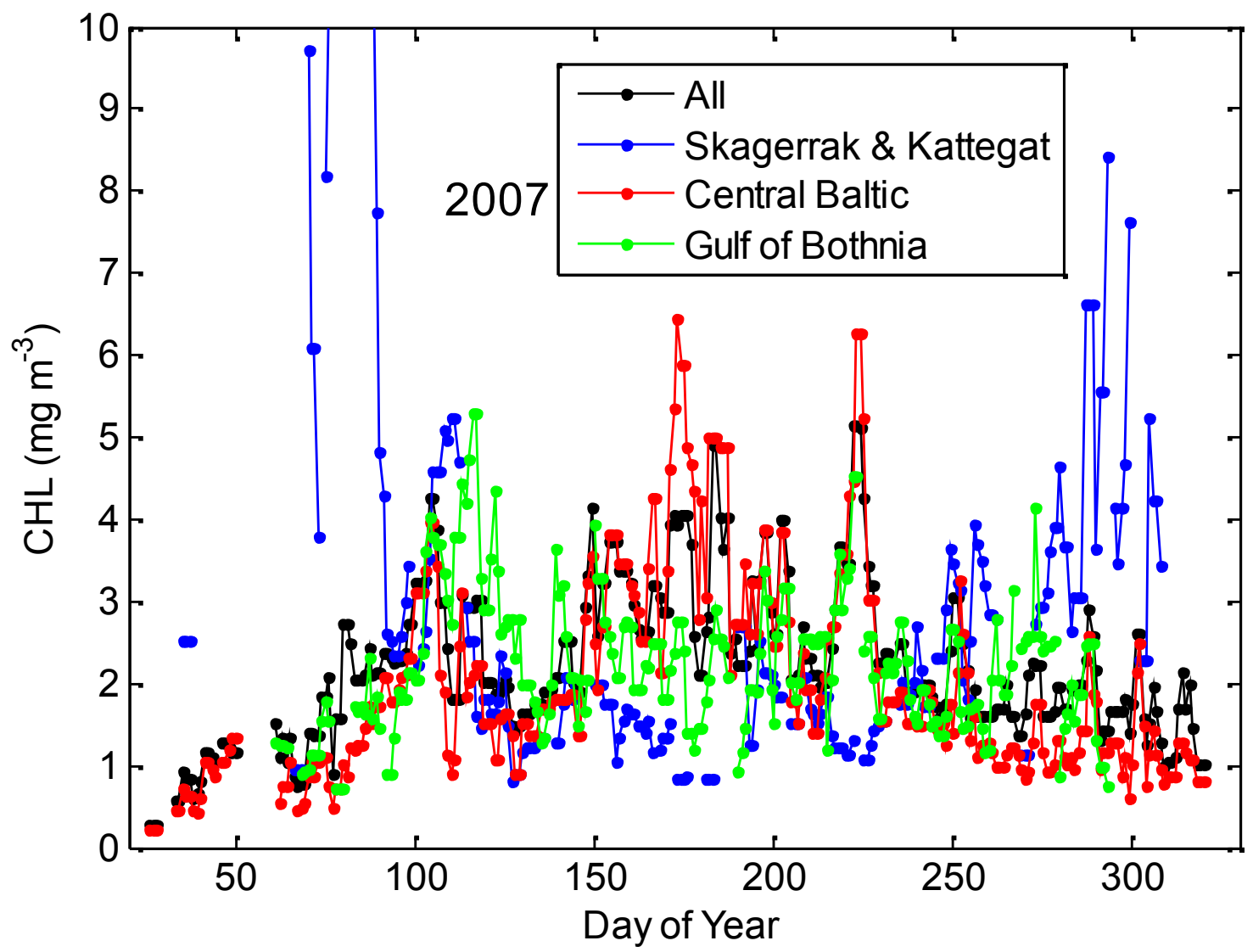

Fig. S10 CHL basin averages in 2007. 


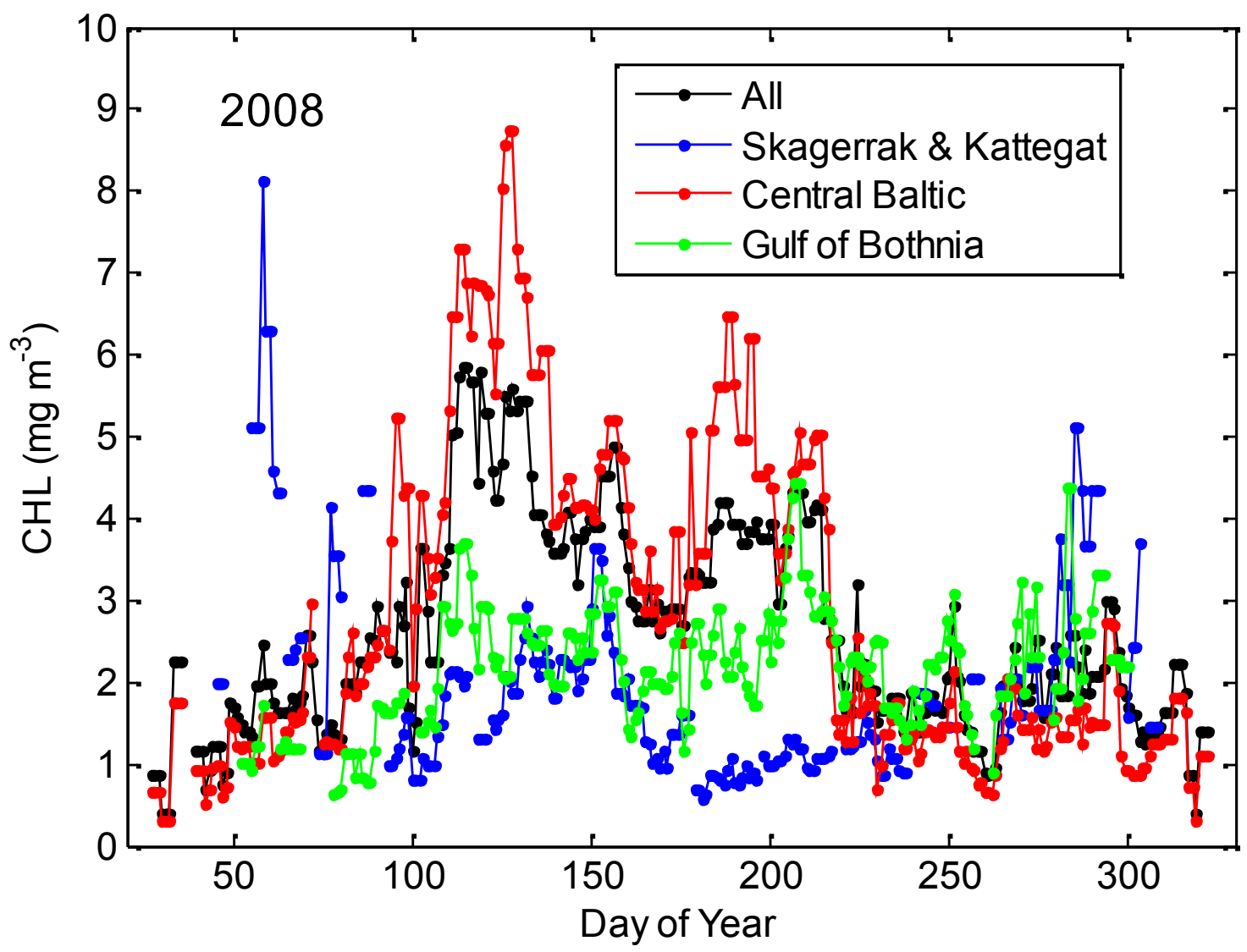

Fig. S11 CHL basin averages in 2008.

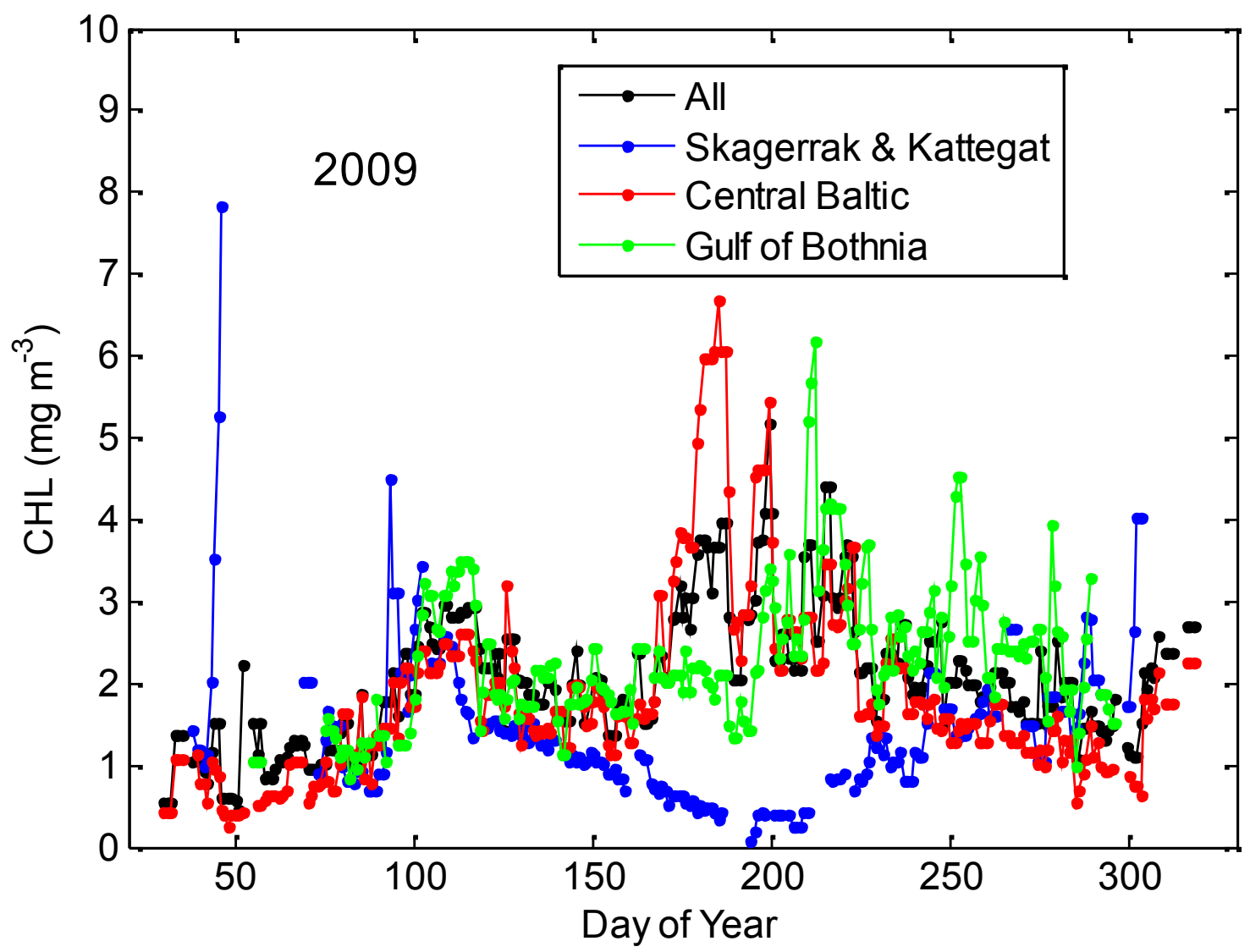

Fig. S12 CHL basin averages in 2009. 


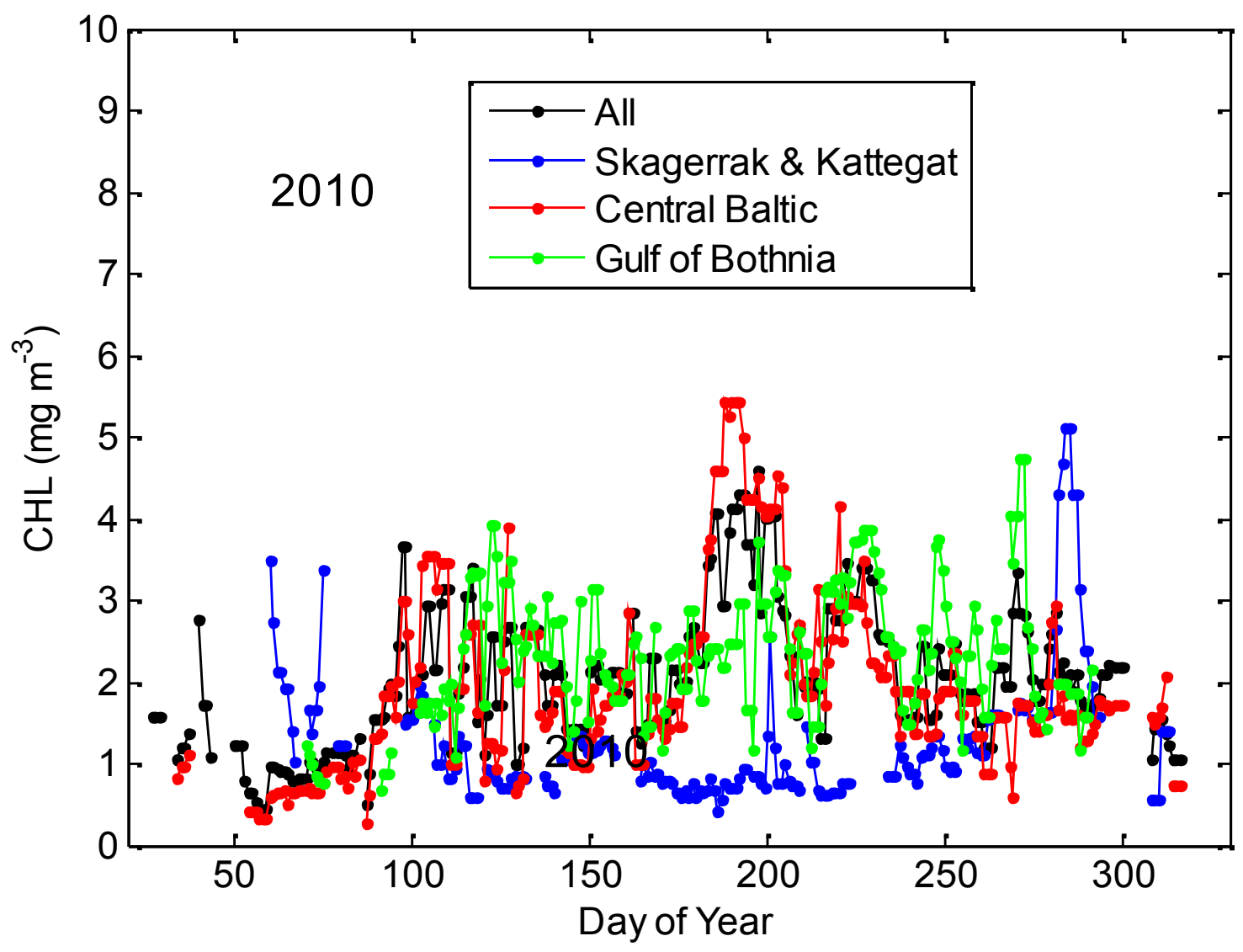

Fig. S13 CHL basin averages in 2010.

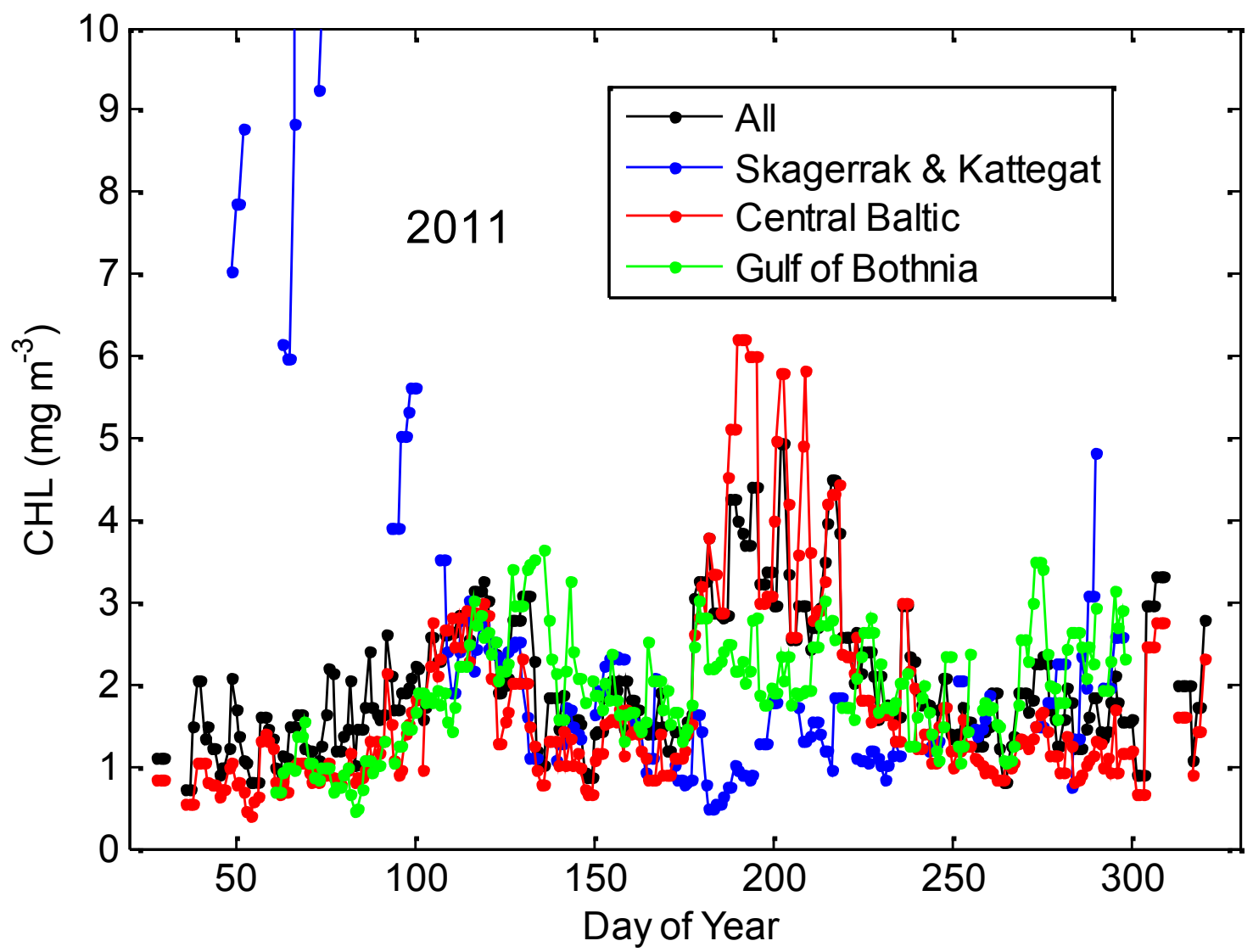

Fig. S14 CHL basin averages in 2011. 


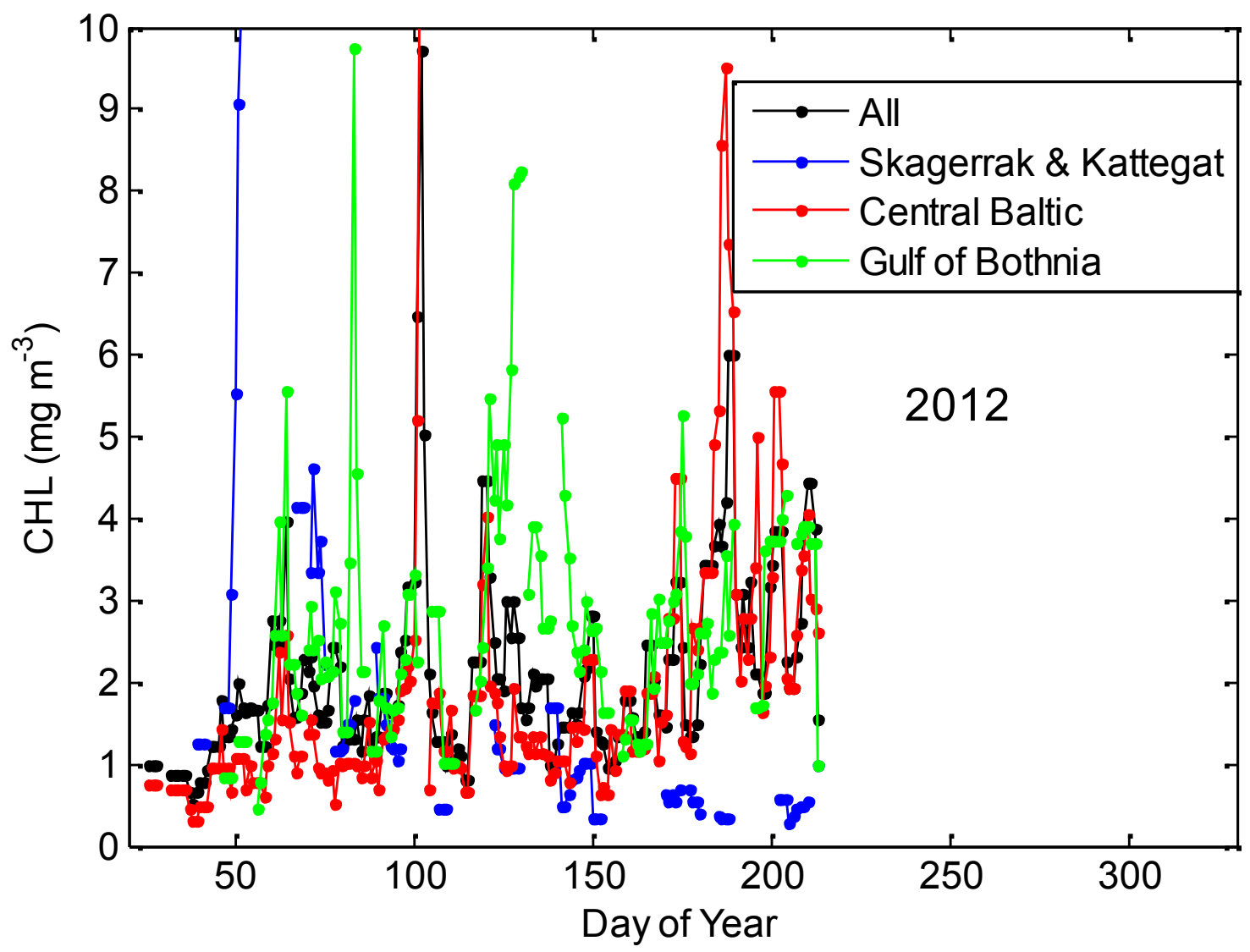

Fig. S15 CHL basin averages in 2012.

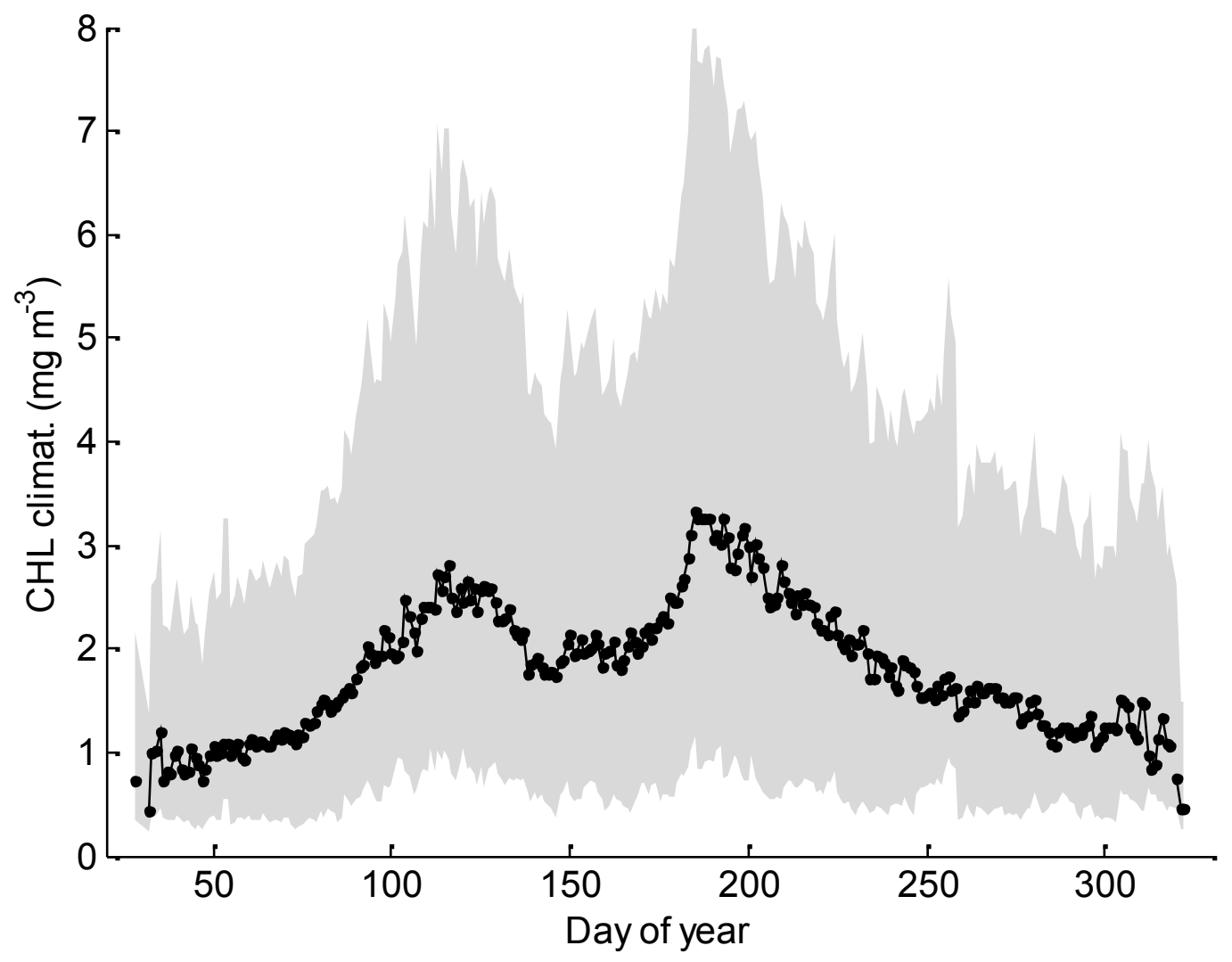

Fig. S16 Climatologic CHL of the whole domain, inside the plus-minus standard deviation band. 


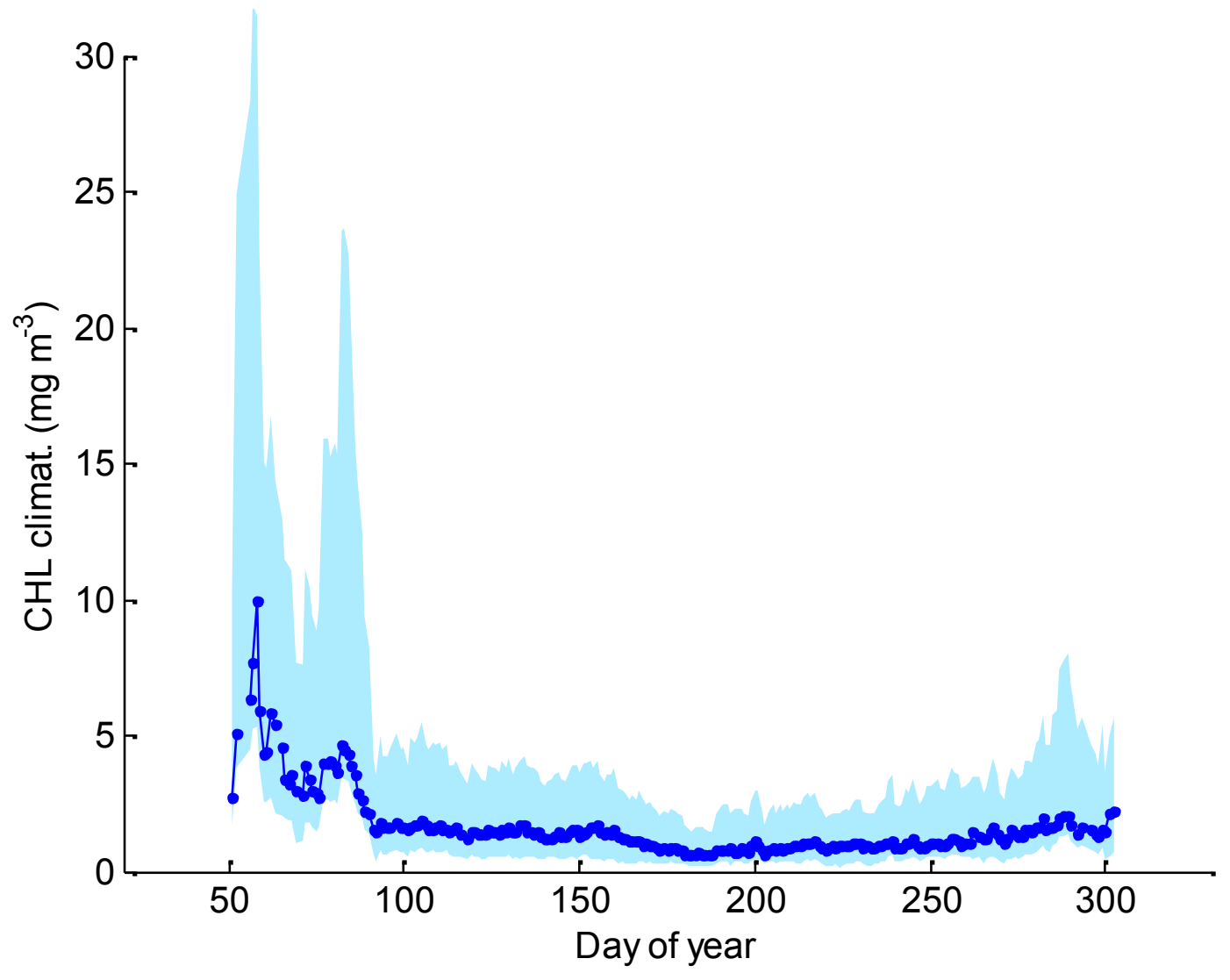

Fig. S17 Climatologic CHL of Skagerrak and Kattegat, inside the plus-minus standard deviation band.

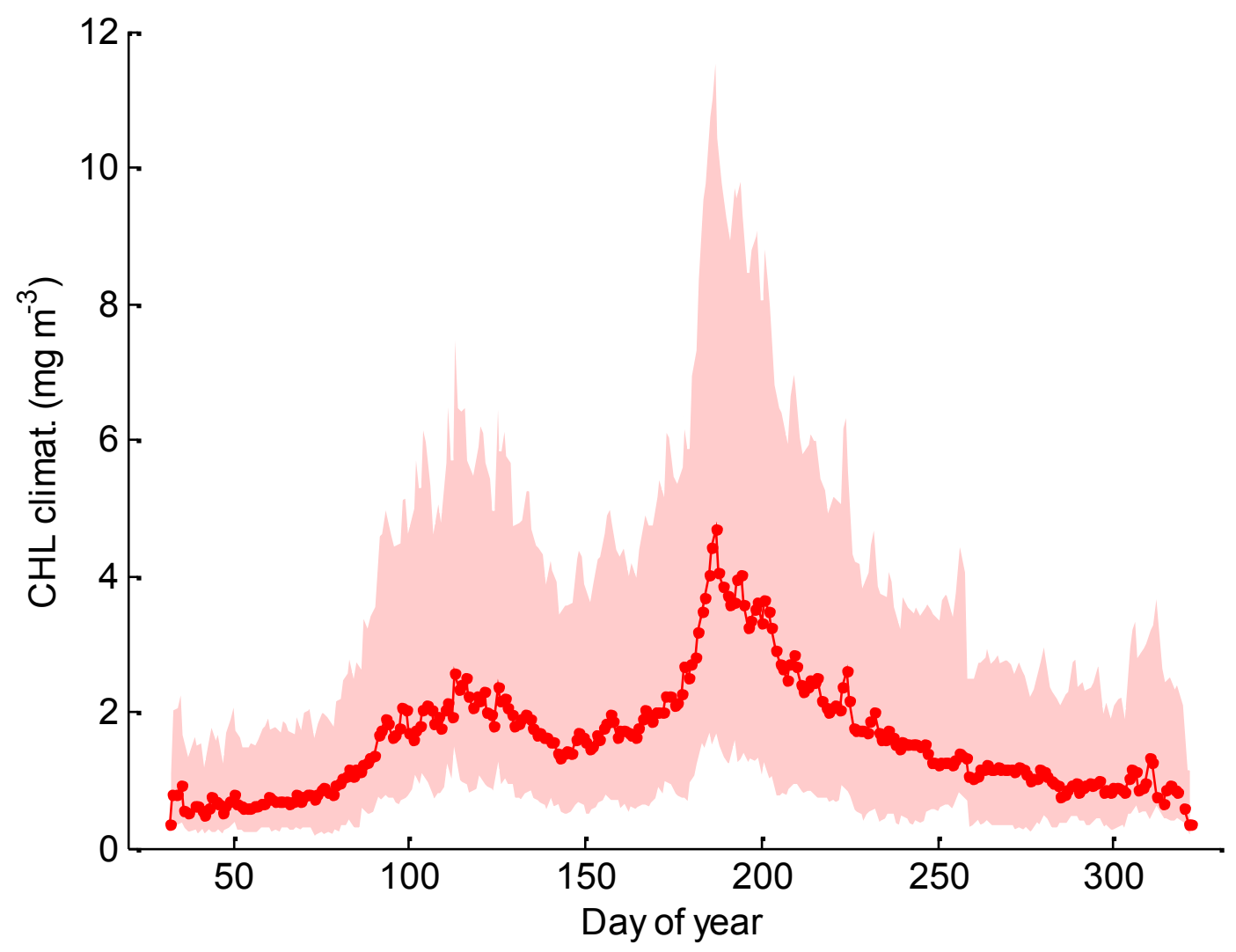

Fig. S18 Climatologic CHL of the Central Baltic, inside the plus-minus standard deviation band. 


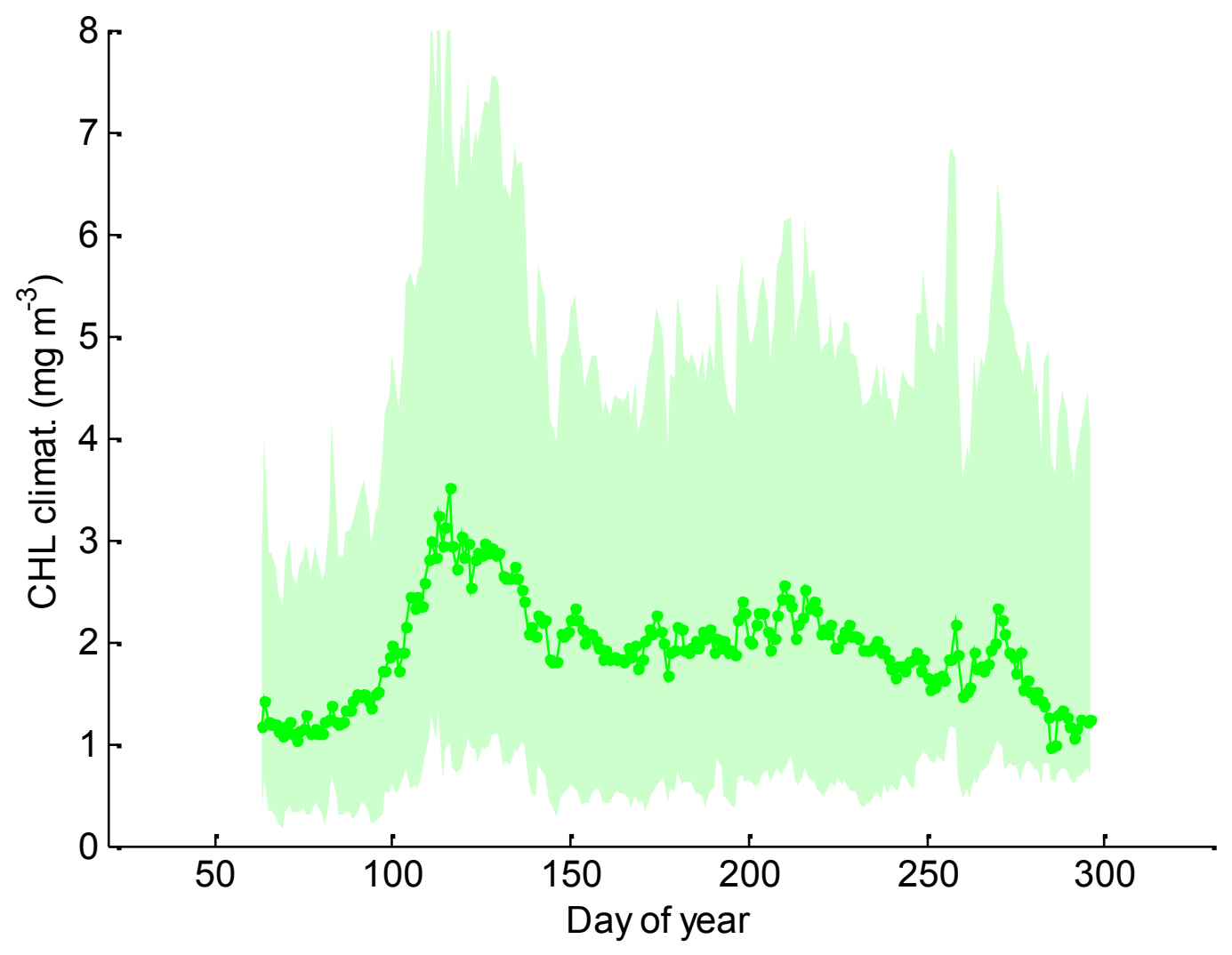

Fig. S19 Climatologic CHL of the Gulf of Bothnia, inside the plus-minus standard deviation band.

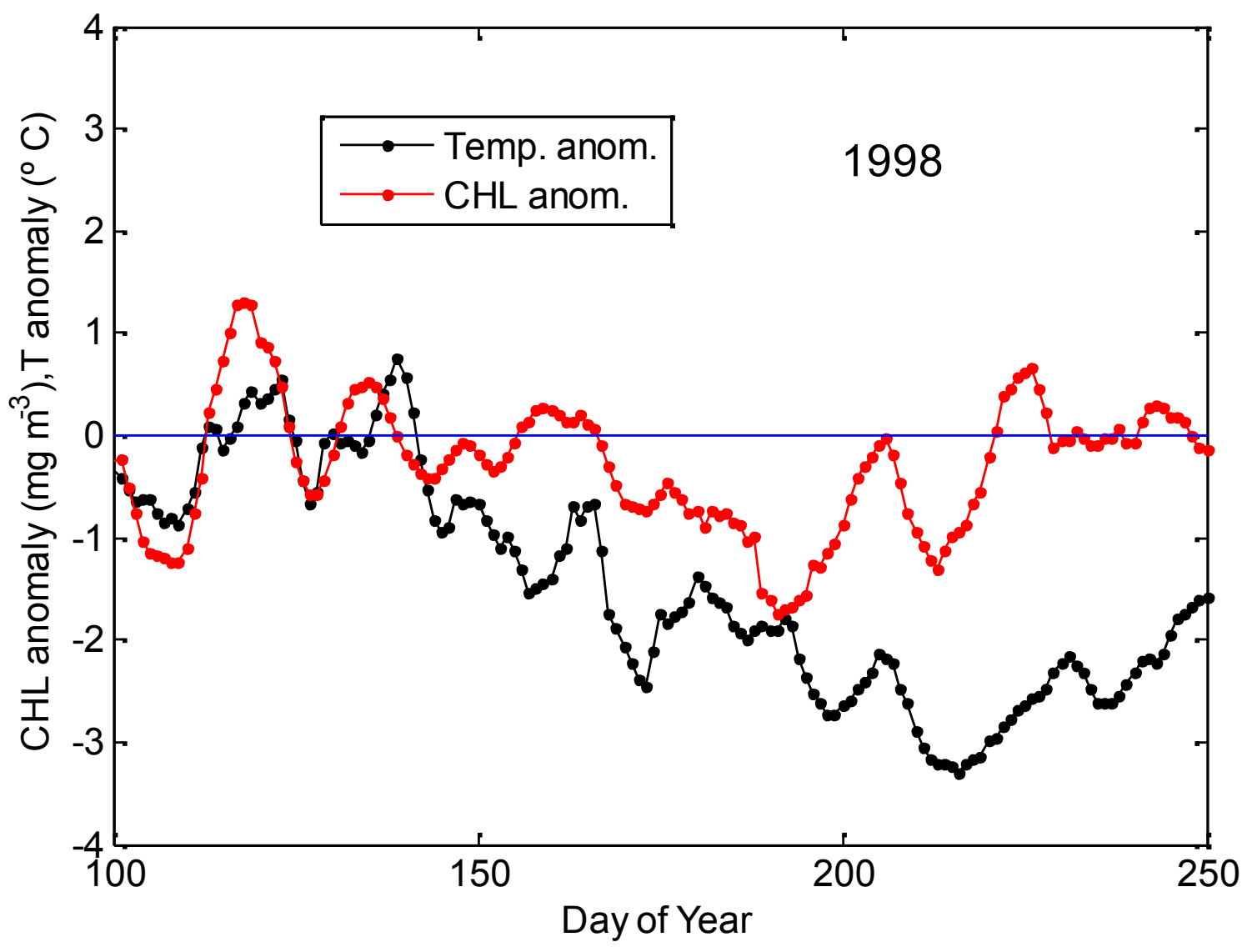

Fig. S20 Anomalies of CHL and SST over climatologies at the Central Baltic. Year 1998. 


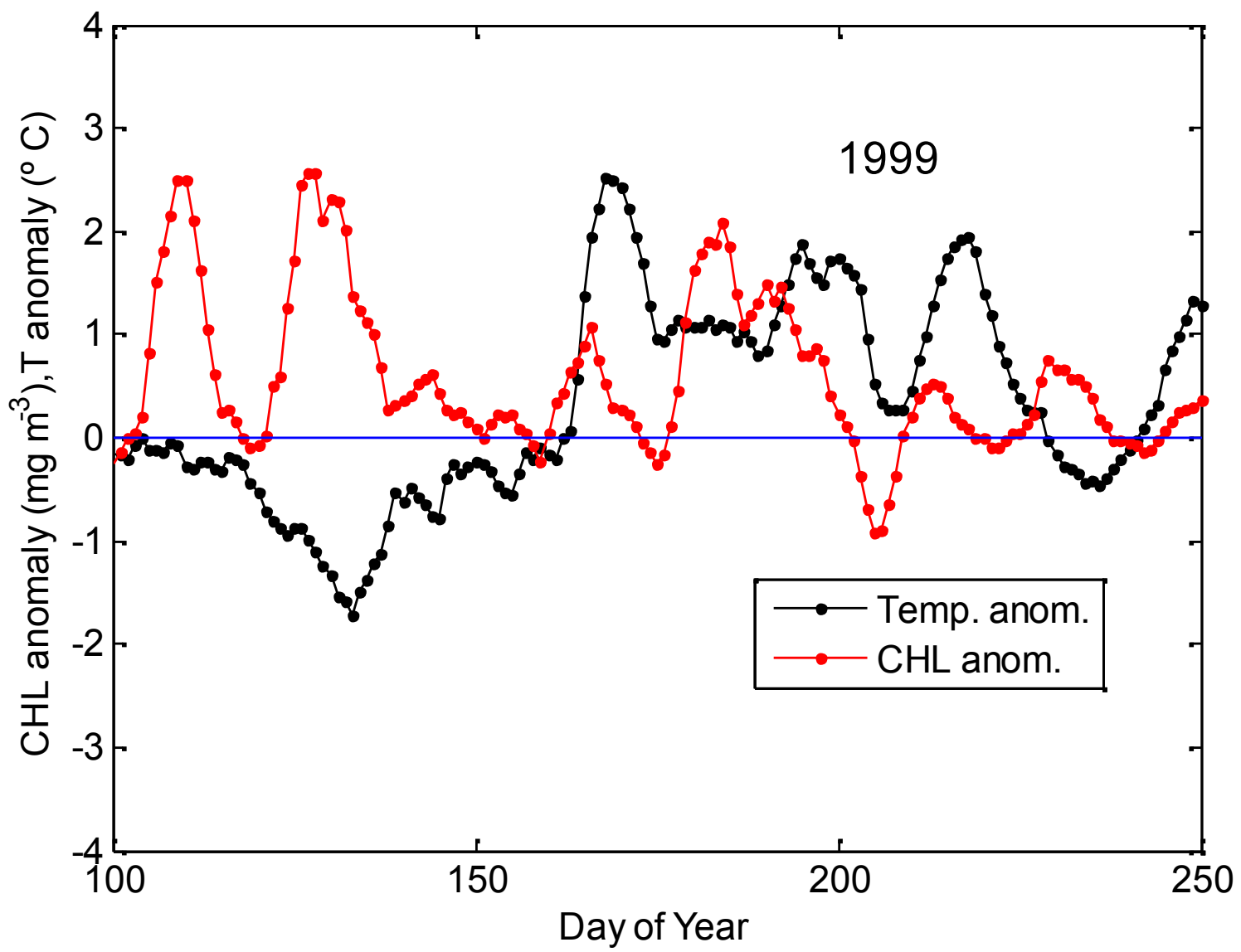

Fig. S21 Anomalies of CHL and SST over climatologies at the Central Baltic. Year 1999.

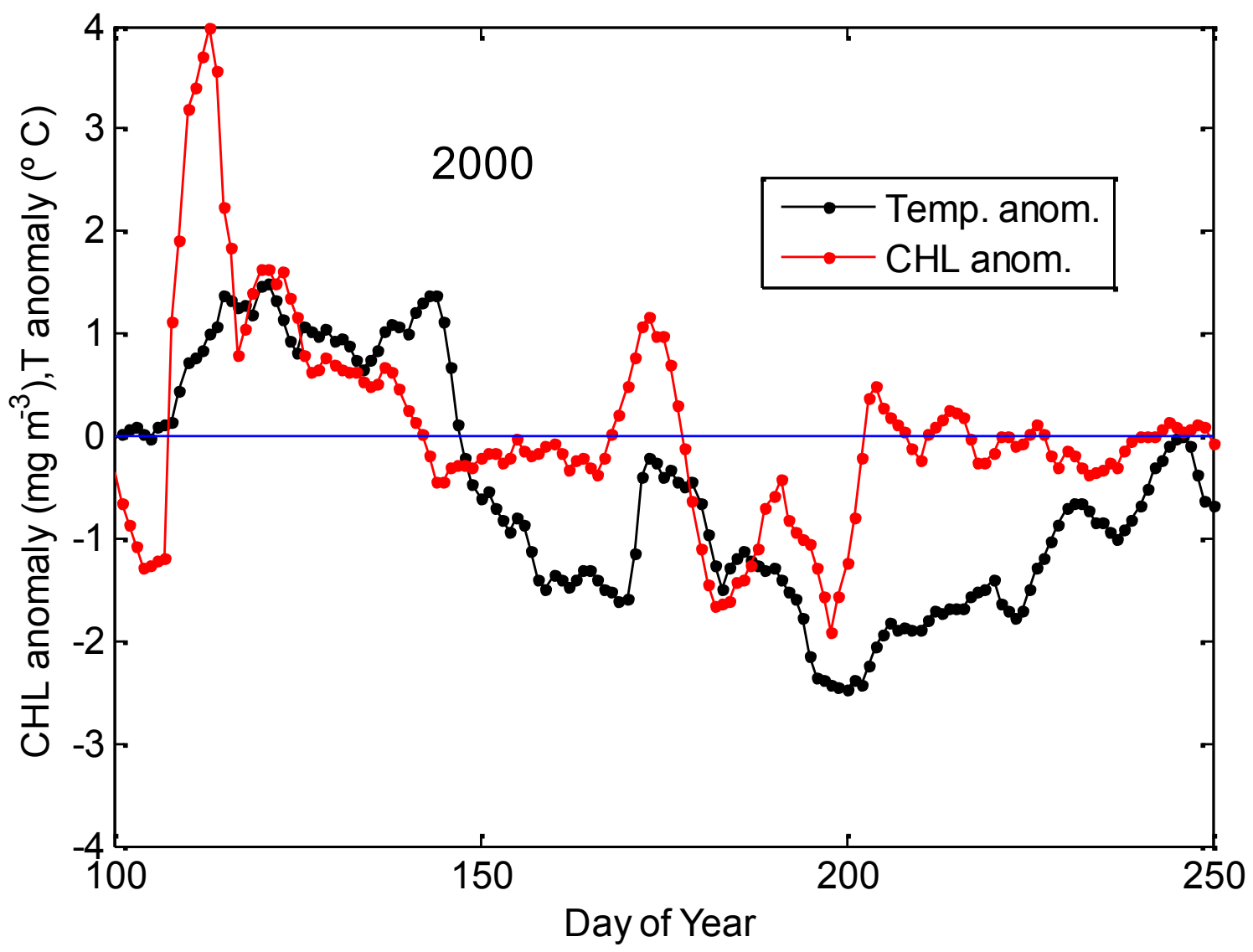

Fig. S22 Anomalies of CHL and SST over climatologies at the Central Baltic. Year 2000. 


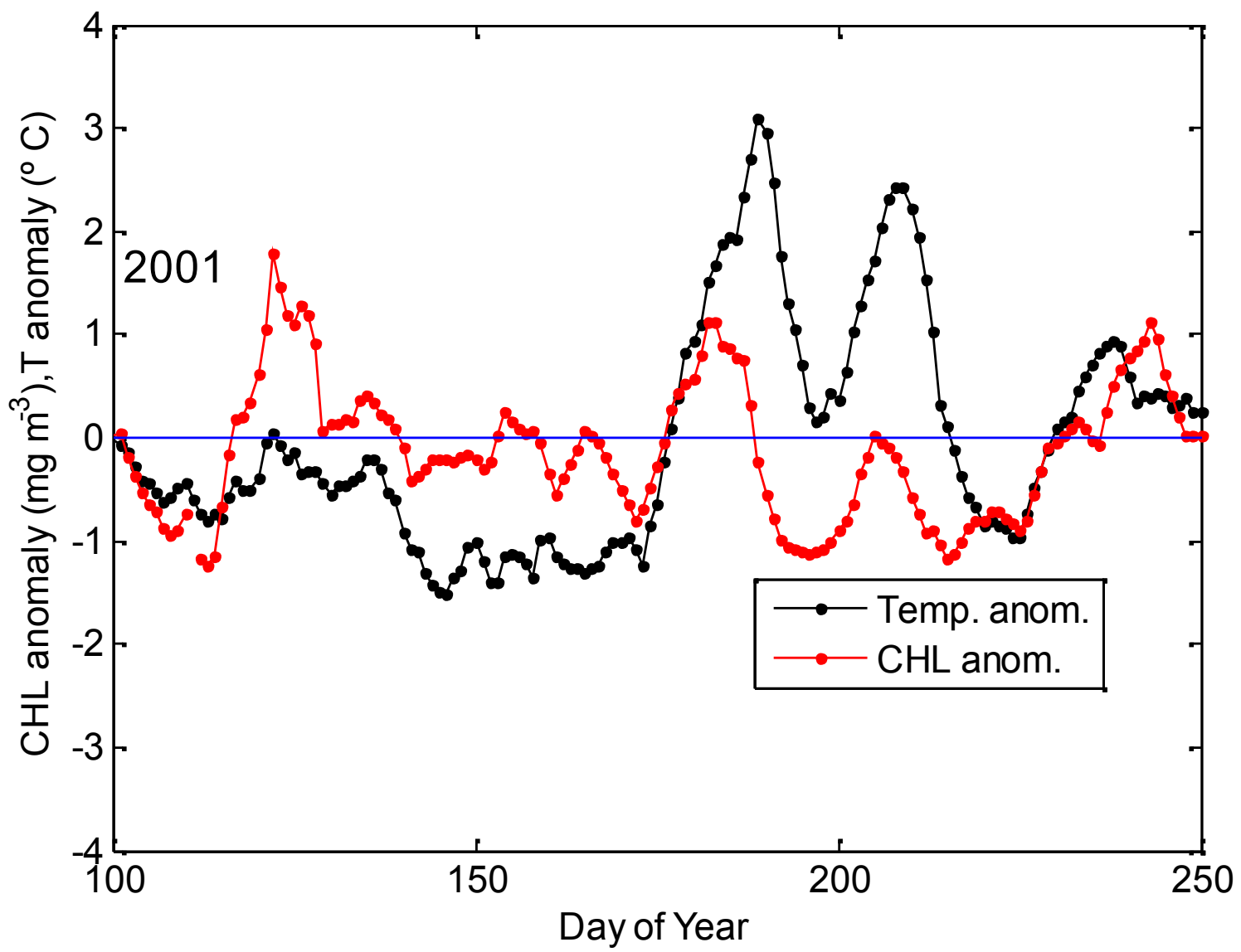

Fig. S23 Anomalies of CHL and SST over climatologies at the Central Baltic. Year 2001.

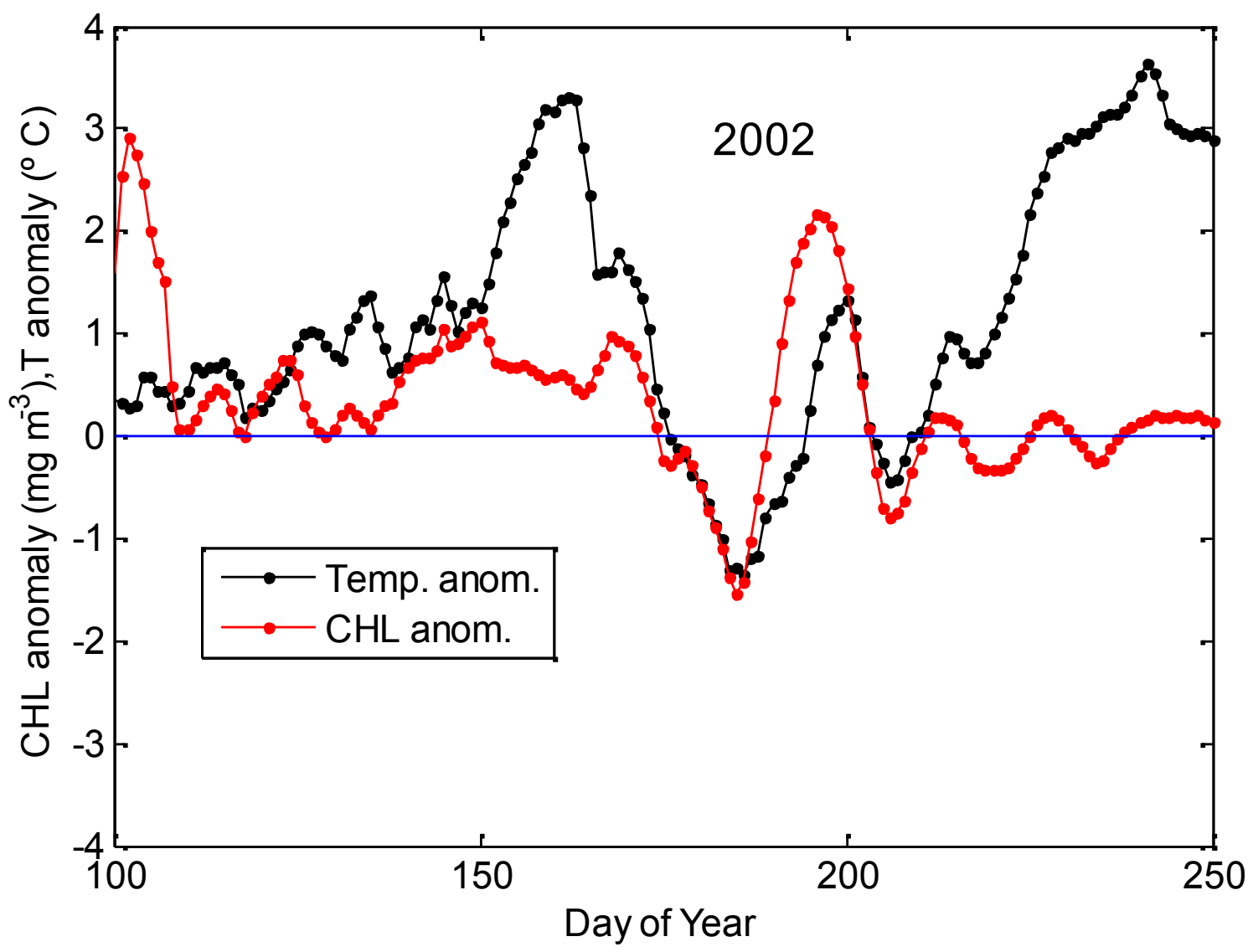

Fig. S24 Anomalies of CHL and SST over climatologies at the Central Baltic. Year 2002. 


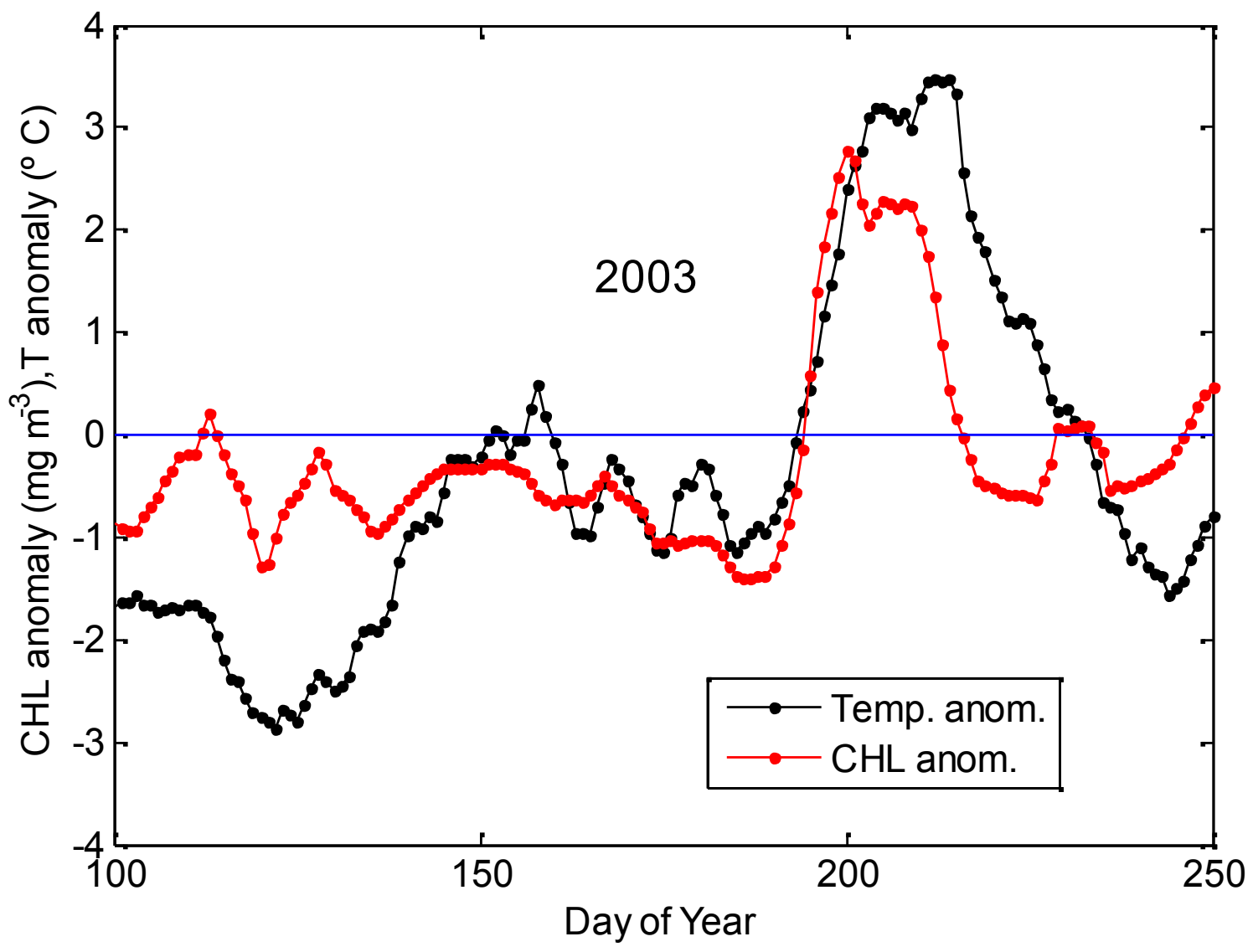

Fig. S25 Anomalies of CHL and SST over climatologies at the Central Baltic. Year 2003.

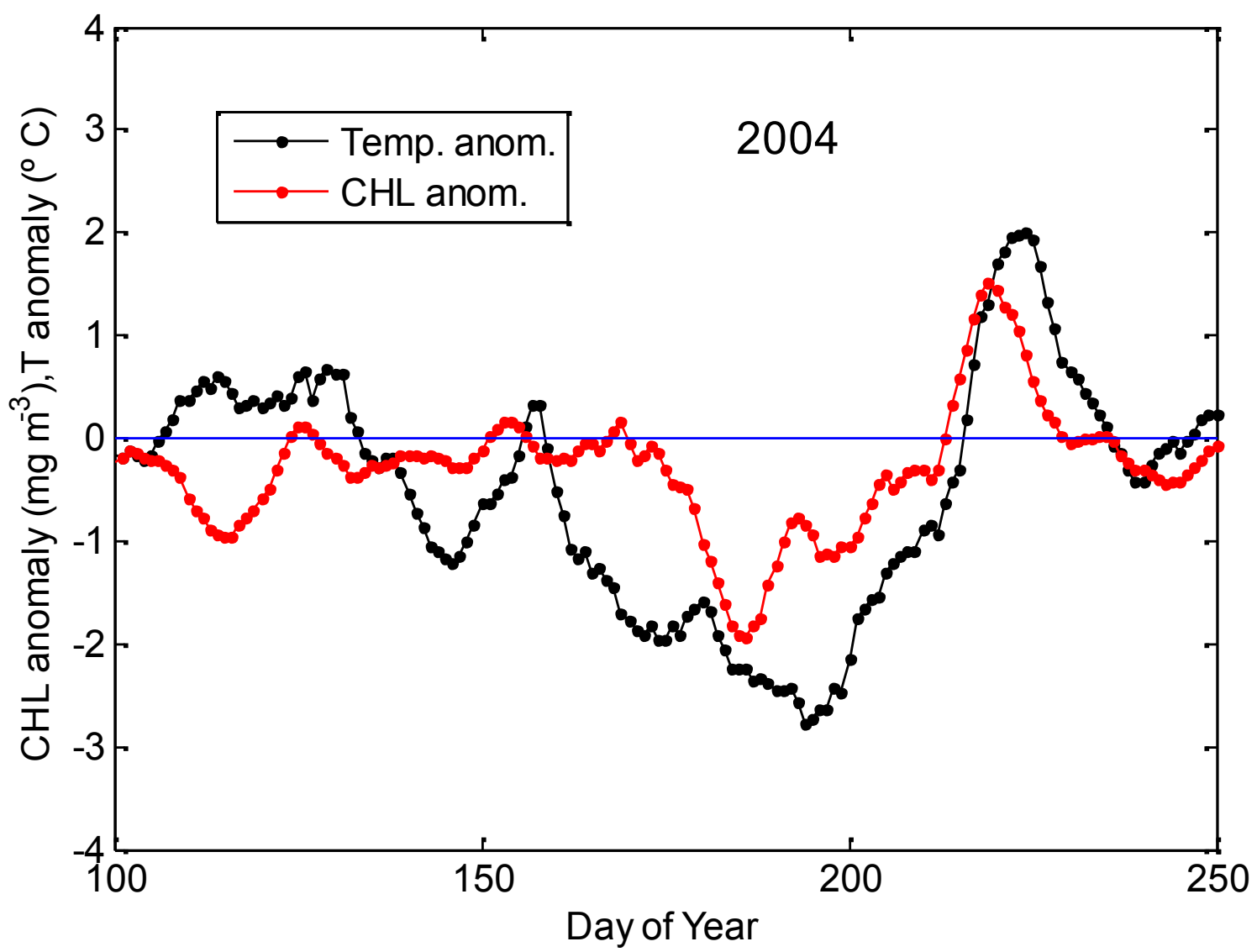

Fig. S26 Anomalies of CHL and SST over climatologies at the Central Baltic. Year 2004. 


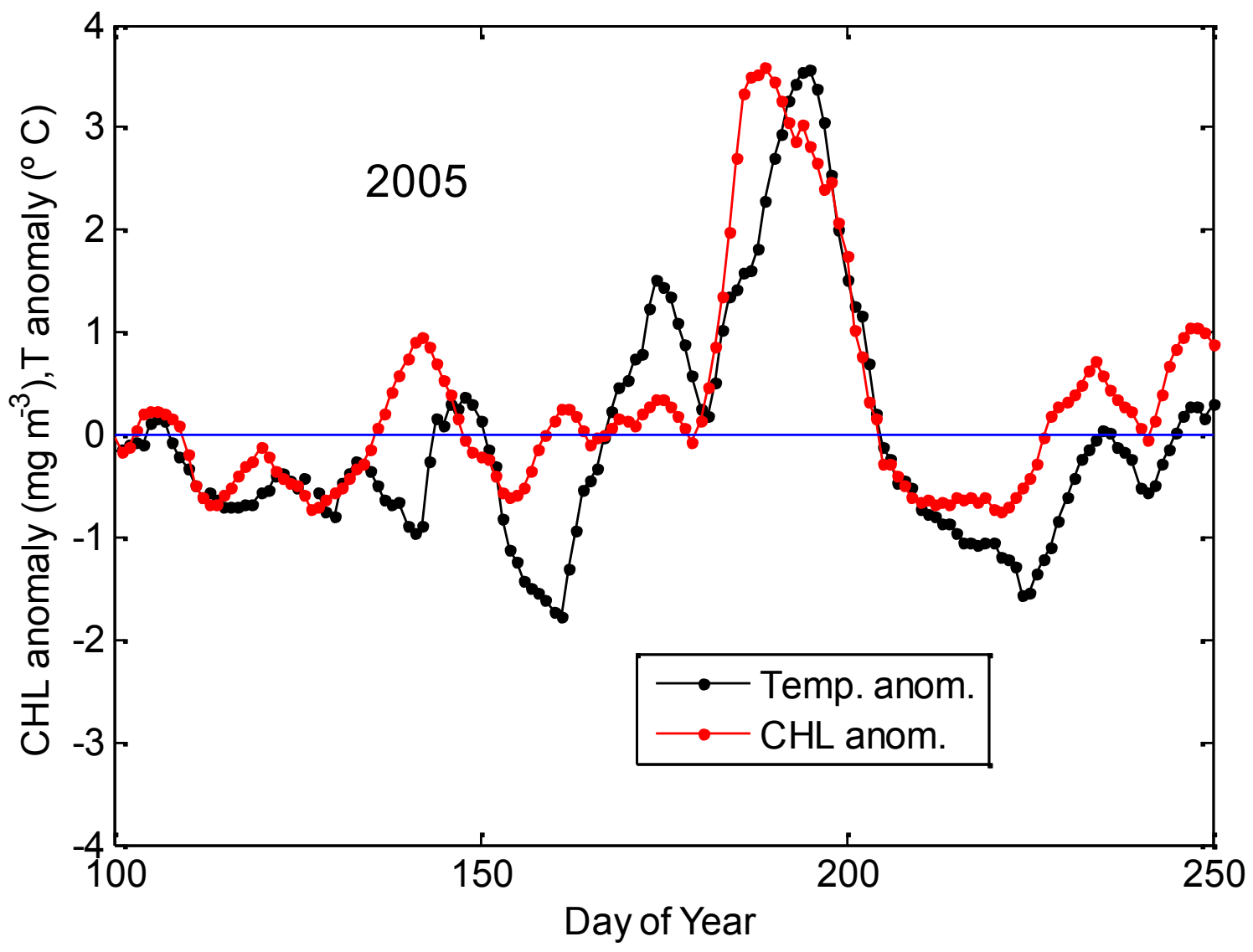

Fig. S27 Anomalies of CHL and SST over climatologies at the Central Baltic. Year 2005.

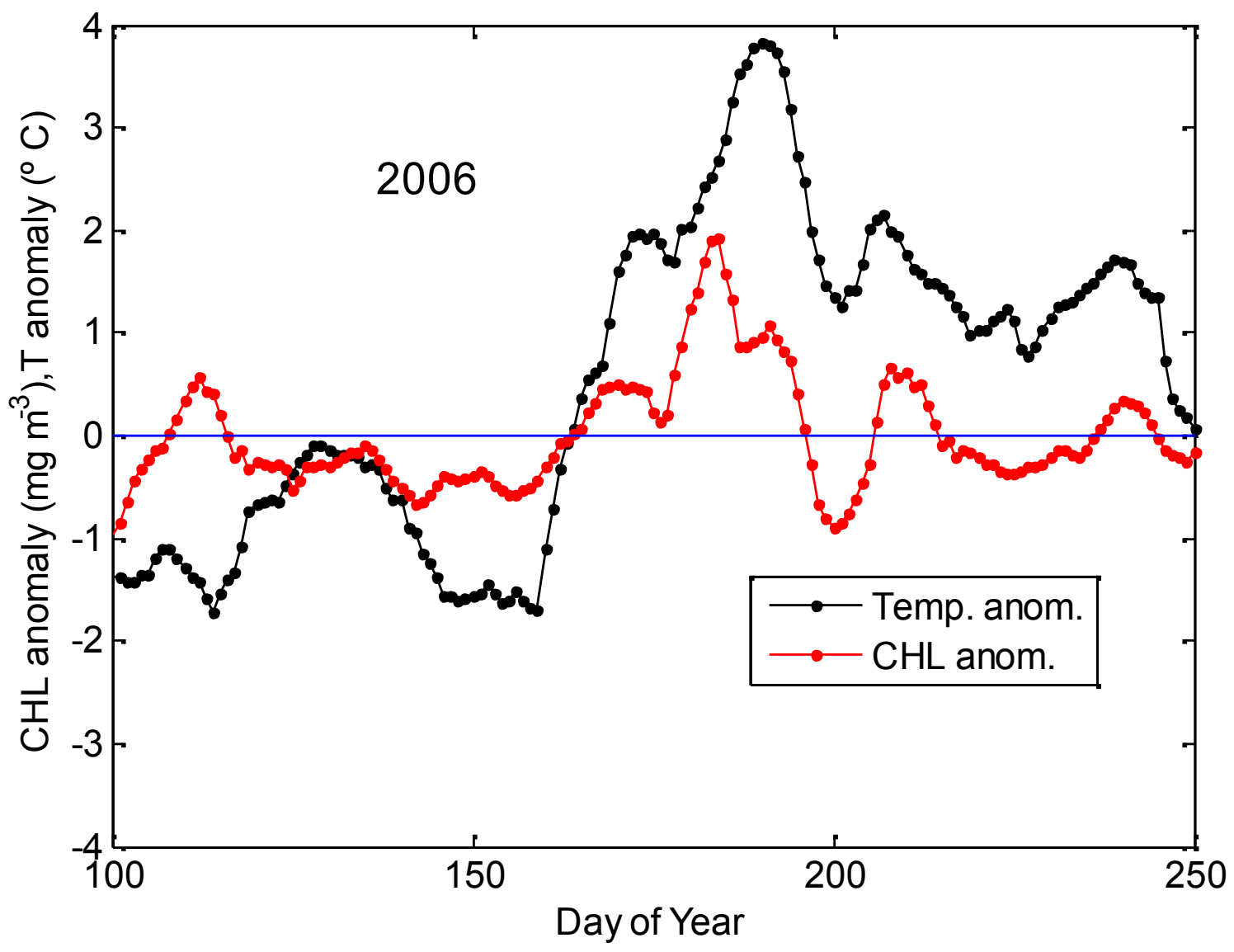

Fig. S28 Anomalies of CHL and SST over climatologies at the Central Baltic. Year 2006. 


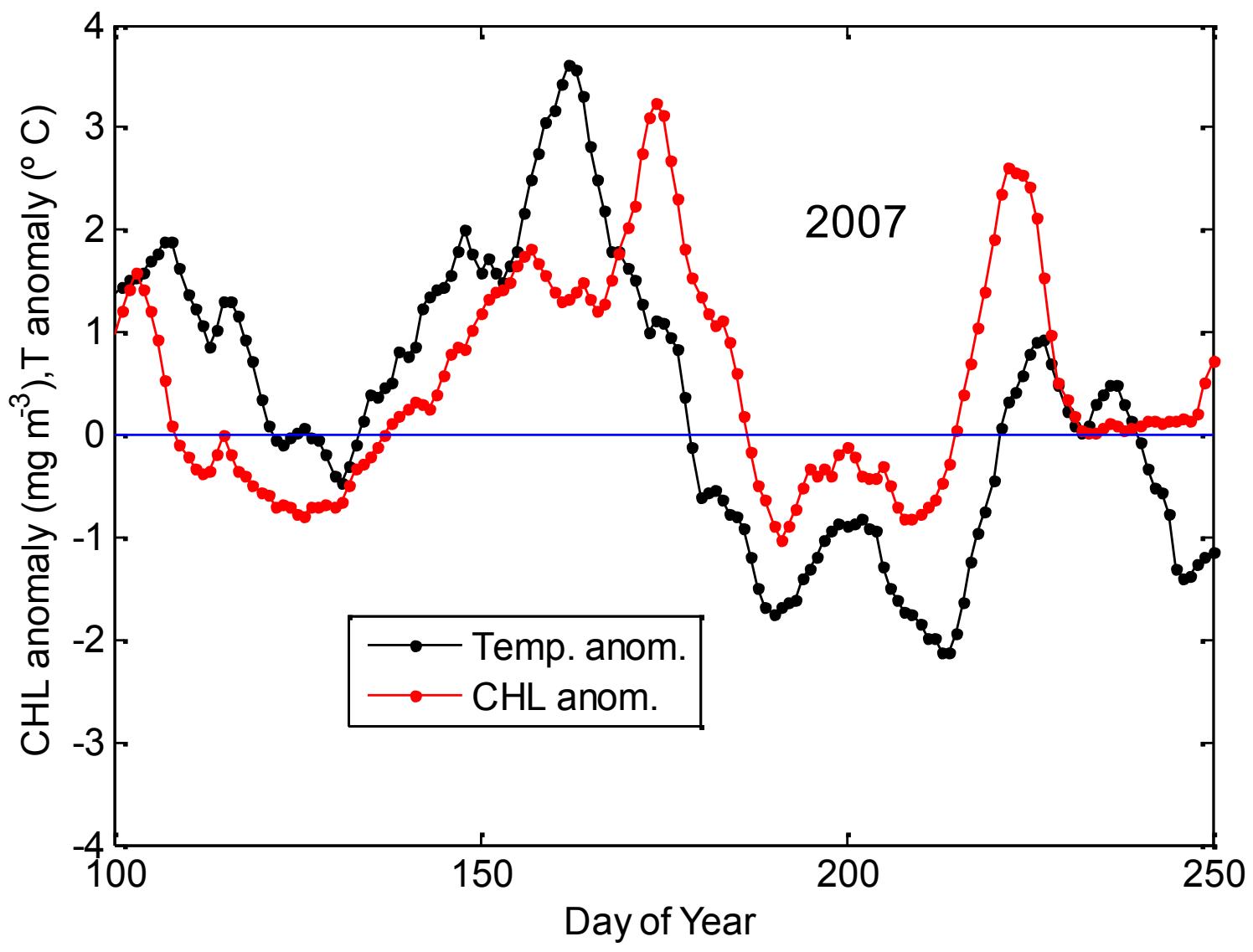

Fig. S29 Anomalies of CHL and SST over climatologies at the Central Baltic. Year 2007.

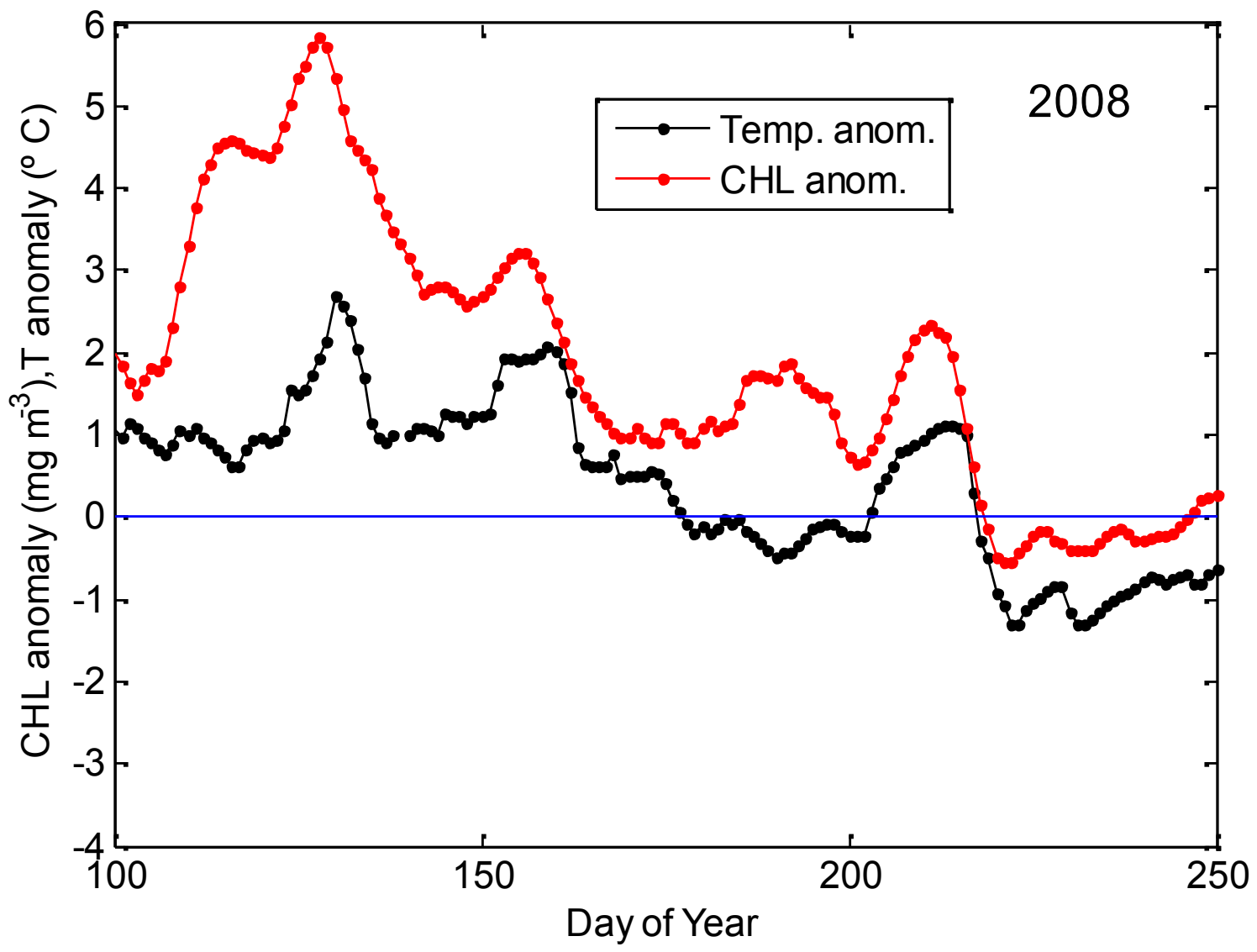

Fig. S30 Anomalies of CHL and SST over climatologies at the Central Baltic. Year 2008. 


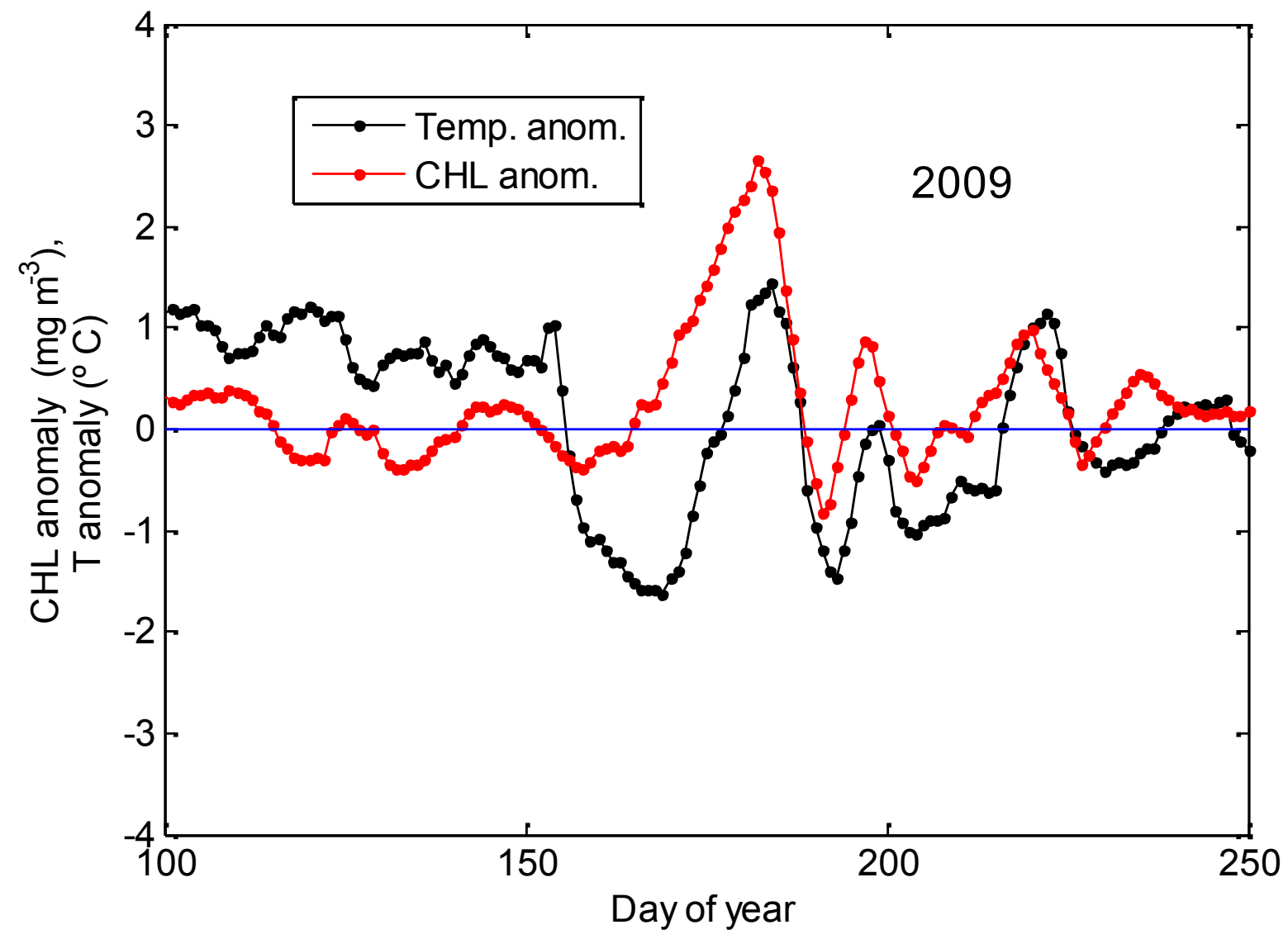

Fig. S31 Anomalies of CHL and SST over climatologies at the Central Baltic. Year 2009.

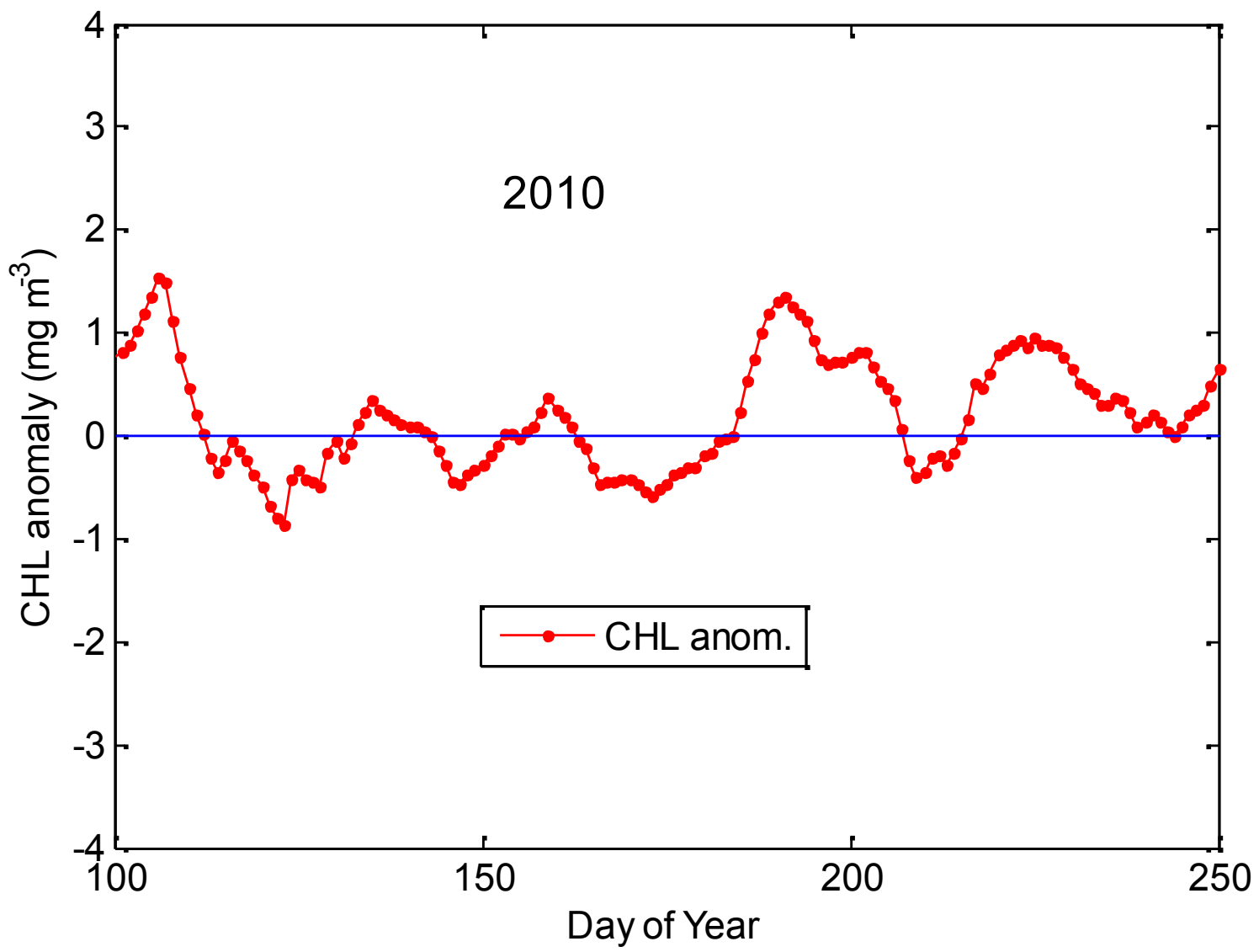

Fig. S32 Anomaly of CHL over climatology at the Central Baltic. Year 2010. 


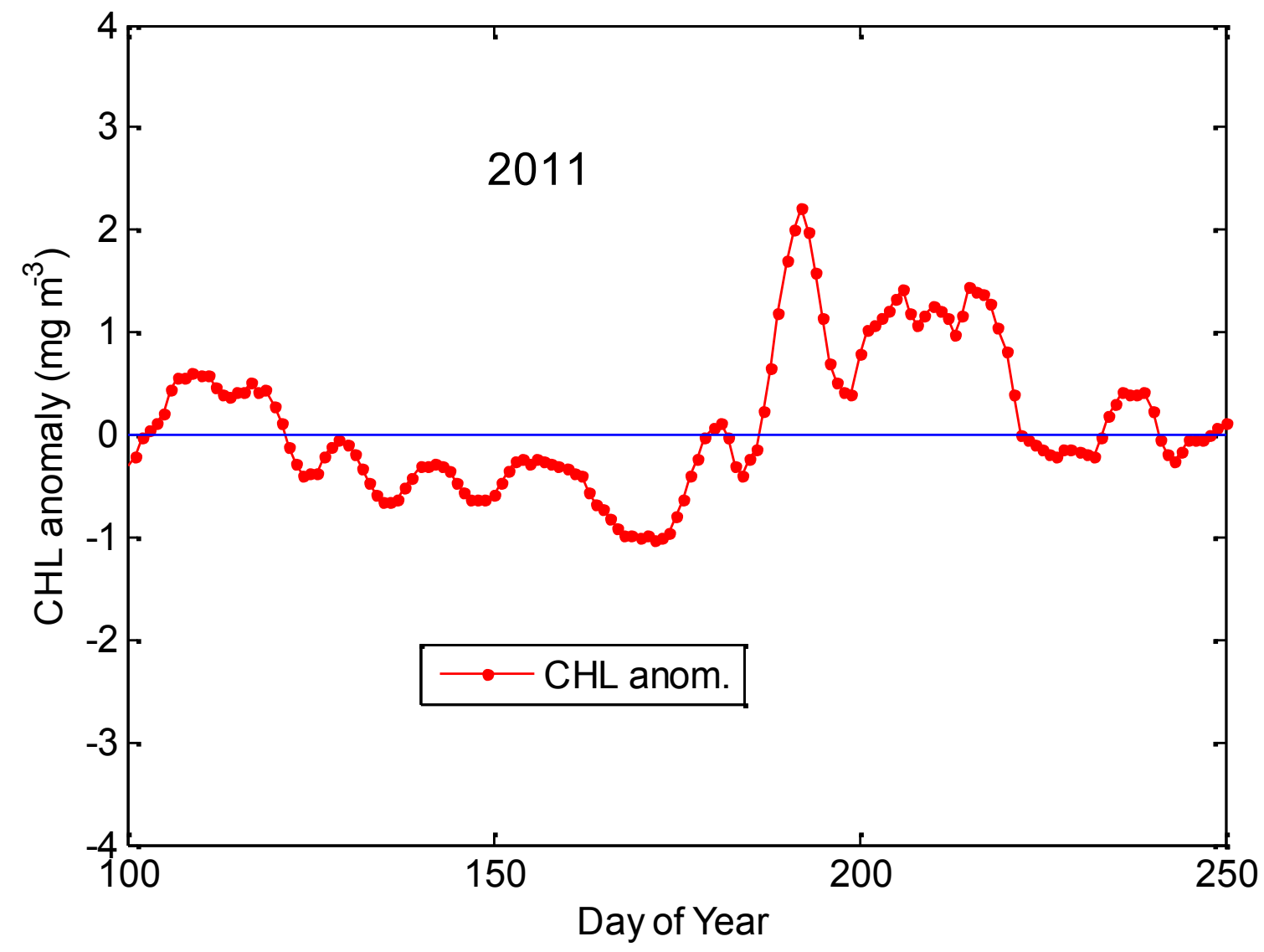

Fig. S33 Anomaly of CHL over climatology at the Central Baltic. Year 2011.

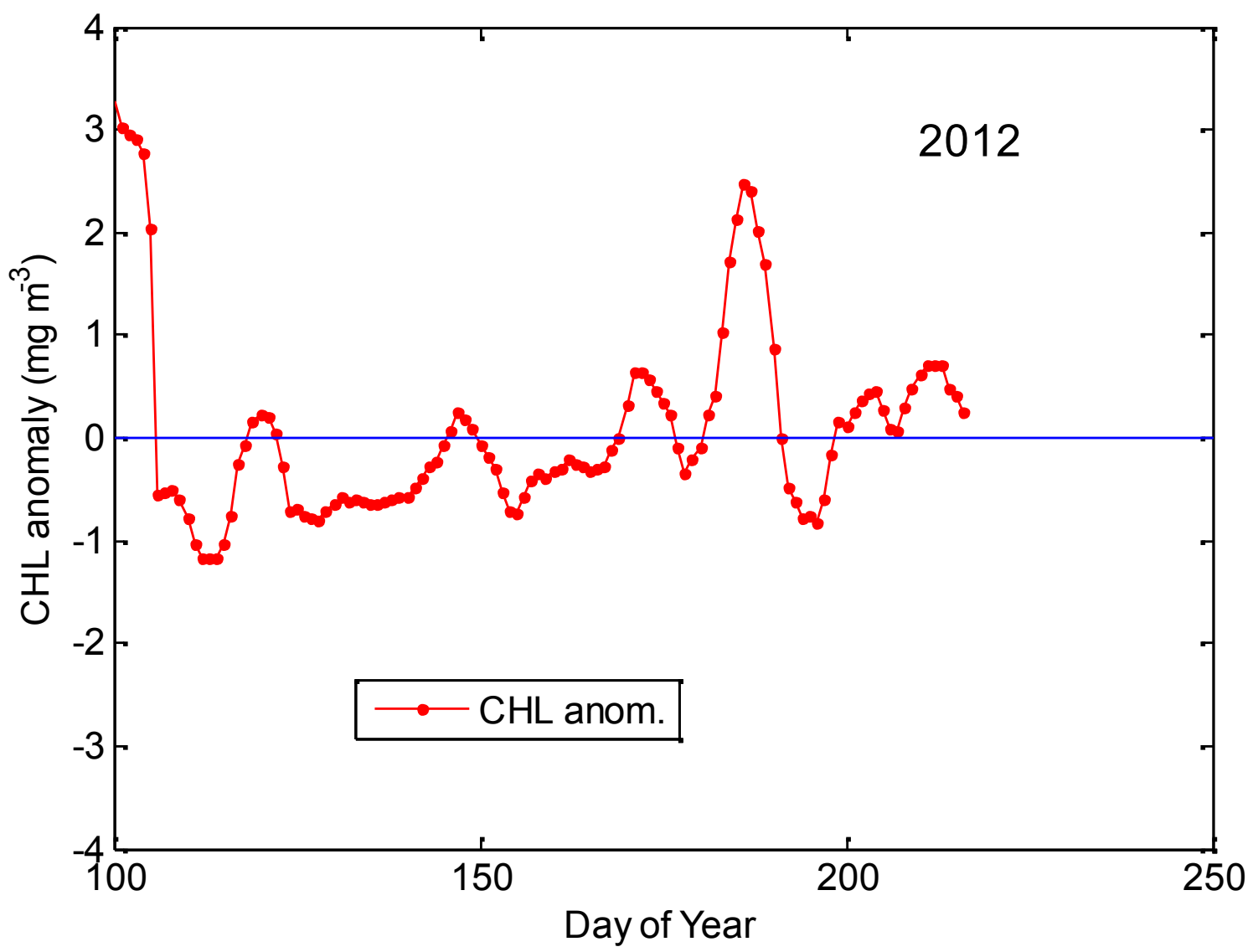

Fig. S34 Anomaly of CHL over climatology at the Central Baltic. Year 2012. 